\title{
Institucionalidad pública para el envejecimiento y las formas de organización residencial ${ }^{1}$
}

\author{
Public Institutions for Aging and Forms of \\ Household Organization
}

\author{
Ángela María Jaramillo* \\ Pontificia Universidad Javeriana, Colombia \\ ORCID: https://orcid.org/oooo-0oo3-3752-5233
}

Fecha de recepción: 2, diciembre, 2016

Fecha de publicación: 25, septiembre, 2017

\section{Resumen}

Uno de los aspectos señalados desde la primera asamblea mundial de envejecimiento es la familia y el hogar. Su importancia se relaciona con los cambios observados en el siglo XX, respecto de la composición de los hogares y su función de apoyo para las personas mayores. Este artículo presenta la forma en que los distintos instrumentos políticos internacionales, regionales y nacionales han abordado la familia y el hogar, así como los desarrollos de la implementación de las acciones de la política nacional de envejecimiento y vejez en este campo, con el objetivo de mostrar las tensiones que existen entre los cambios residenciales en la vejez y las acciones orientadas hacia la regulación de sus implicaciones, en una perspectiva de derechos. La identificación de los avances y las tensiones de la implementación de la política nacional constituye un aporte para el proceso de la institucionalidad pública del envejecimiento y los arreglos residenciales, en la medida en que señalan brechas entre hábitos

\section{Abstract}

One of the aspects pointed out since the First World Assembly for Aging is the family and the households. Its importance is related to the changes observed in the 2oth century, regarding the composition of households and their support function for the elderly. This article presents the way in which the different international, regional and national political instruments have addressed the family and the households, as well as the developments of the implementation of the actions of the national policy of aging and old age. It has the aim of showing the tensions that exist between residential changes in old age and actions oriented towards the regulation of their implications, in a rights perspective. The identification of the advances and tensions of the implementation of the national policy constitutes a contribution to the process of the public institutionality of aging and residential arrangements, and the gaps are pointed between social habits and the regulatory frameworks that

doi:10.11144/Javeriana.papo23-1.ipef

*Autor de correspondencia: jaramillo-angela@javeriana.edu.co 
sociales y los marcos normativos que los regulan y orientan. Para este trabajo, se utilizaron fuentes documentales y entrevistas realizadas a profesionales ${ }^{2}$ que han trabajado en la formulación e implementación de la política nacional y académicos ${ }^{3}$ que se dedican a la investigación del envejecimiento y la vejez en el país.

\section{Palabras clave}

Envejecimiento; vejez; familia; hogar; política social

\section{Cómo citar este artículo:}

Jaramillo, A. M. (2018). Institucionalidad pública para el envejecimiento y las formas de organización residencial. Papel Político, 23(1), 35-90. https://doi.org/10.11144/Javeriana. papo23-1.ipef regulate and guide them. The sources for this work were institutional documents, interviews with professionals who have worked in the formulation and implementation of national policy, and academics who are dedicated to the investigation of aging and old age in the country.

\section{Keywords}

Aging; old age; households; family; social policy 


\section{Introducción}

Una de las principales características de las sociedades contemporáneas es la longevidad humana. Esta condición hace parte de los desarrollos sociales observados en el mundo durante los siglos XX y XXI. Constituye un importante desafío para las actuales formas de organización social, orientadas, en especial, por las edades de formación para el trabajo y las económicamente productivas. Tal orientación ha dejado de lado las edades maduras, que, gracias al avance de la longevidad, son cada vez más frecuentes en las sociedades contemporáneas. El tercer propósito de los 17 Objetivos de Desarrollo Sostenible, propuesto por la Organización de las Naciones Unidas (ONU, 2015) es garantizar una vida saludable y promover el bienestar para todos en todas las edades. El logro de este objetivo es un desafío para la institucionalización del envejecimiento humano como proceso que se inicia cuando las personas nacen y finaliza cuando mueren. La concepción del curso de vida implica la superación de las condiciones sociales que han posibilitado la fragmentación de la vida humana en etapas etarias (infancia, juventud, adultez y vejez) y económicamente productivas y no productivas. De tal manera que la edad no sea una razón de discriminación y sufrimiento para los seres humanos.

Las instituciones se entienden como un instrumento del Estado orientado hacia la reducción de las brechas de protección y bienestar entre las personas y la creación de condiciones de posibilidad que faciliten la realización de cada ser humano. Su deber es administrar y brindar servicios públicos para toda la población, independiente de las condiciones de poder y riqueza de las personas (Comisión Económica para América Latina y el Caribe [Cepal], 2012b). Dentro de los aspectos más importantes de las instituciones, se encuentran su sentido e influencias. El primero se construye a partir de los significados y las orientaciones morales y éticas que definen el problema que les da origen y el segundo se relaciona con el poder de los actores que toman las decisiones sobre los problemas. Dependiendo de estos aspectos, se construyen las agendas de gobierno y se posicionan los distintos asuntos de interés, como las personas mayores. Esto muestra la complejidad que enfrenta la institucionalización del envejecimiento, en la medida en que es un proceso que involucra las distintas lógicas de los actores que definen los problemas, los incluyen en las agendas, posicionan en los debates públicos y toman decisiones. Además de la necesaria coordinación entre las diferentes lógicas, se requiere una articulación entre los hábitos sociales y los marcos normativos que los regulan y orientan. El avance hacia una institucionalidad pública para el envejecimiento demanda su integración en el ambiente de las políticas públicas como la creación e implementación de programas, prestaciones y servicios que respondan de forma oportuna y adecuada al problema (Cepal, 2012).

Los avances hacia la institucionalización del envejecimiento humano en el mundo comenzaron hace más de treinta años, con la elaboración de instrumentos políticos 
internacionales (Asamblea Mundial sobre el Envejecimiento. 26 julio a 6 de agosto de 1982 Viena, Austria), que buscaban posicionar el envejecimiento demográfico en las agendas regionales y nacionales y establecer lineamientos para responder a los retos de sociedades multigeneracionales. También se elaboraron instrumentos regionales (Conferencia regional intergubernamental sobre envejecimiento: hacia una estrategia regional de implementación para América Latina y el Caribe Plan de Acción Internacional de Madrid sobre el Envejecimiento; Declaración de Brasilia. Segunda Conferencia regional intergubernamental sobre envejecimiento en América Latina y el Caribe: hacia una sociedad para todas las edades y de protección social basada en derechos. Brasilia, 4 al 6 de diciembre de 2007; Segunda Reunión de seguimiento de la Declaración de Brasilia), cuyo propósito era articular los problemas mundiales del envejecimiento con las particularidades de la región de América Latina y el Caribe.

Colombia hace parte de los países que han participado en la elaboración de los instrumentos regionales. A nivel nacional, se han desarrollado varios avances legislativos y políticos a favor de la protección de los derechos económicos, sociales y culturales de las personas mayores: Ley 29/1975, de 25 de septiembre; artículo 46 de la Constitución Política de 1991; Política Nacional de Envejecimiento y Vejez 2007-2019; Metodología Integrada de Participación Social de y para Adultos Mayores (MIPSAM); Política Colombiana de Envejecimiento Humano y Vejez 2014-2024; Programa Nacional de Alimentación Complementaria al Adulto Mayor “Juan Luis Londoño de la Cuesta” (PPSAM); Programa Nacional de Alimentación para el Adulto Mayor “Juan Luis Londoño de la Cuesta” (PNAAM), Programa Nuevo Comienzo, "Otro motivo para vivir”; Programa de Capacitación a las Personas Mayores en las Tecnologías de la Información y las Comunicaciones; Formación para el Trabajo, generación de ingresos para jóvenes y la ley del primer empleo; Ley 1091/2006, de 8 de septiembre; Ley 1171/2007, de 7 de diciembre; Ley 1251/2008, de 27 de noviembre; Ley 1276/2009, de 5 de enero; Ley 1315/2009, de 13 de julio (Cepal, 2012).

Uno de los aspectos señalados desde la primera asamblea mundial de envejecimiento es la familia y el hogar. Su importancia se relaciona con los cambios en la composición de los hogares y su función de apoyo para las personas mayores. Durante el siglo XX, Colombia registró una significativa reducción de la fecundidad que, en combinación con la transformación de los sentidos de obligación en las familias, posibilitaron importantes cambios en las formas de residencia de las personas mayores. Hace cien años era muy común que los ancianos vivieran en hogares extensos con hijos y otros parientes. Actualmente, una de cada dos personas mayores viven solos o exclusivamente con sus parejas, es decir, la convivencia con los hijos u otros familiares ha observado una importante disminución, lo que abre paso a los hogares independientes en la vejez. Tal cambio requiere una institucionalidad pública que garantice solidaridades institucionales/formales y comunitarias que reemplacen y complementen las solidaridades tradicionales 
que ofrecían los grupos familiares extensos orientados por un sentido de obligación en el que era normal que uno de los hijos, por lo general la hija mayor o menor, se hiciera cargo de la vejez de sus padres (Jaramillo, 2017).

En el contexto contemporáneo, son cada vez más escasos los grupos familiares extensos (diez o más hijos) y se ha desvalorizado la obligación de cuidar al otro, en la medida en que es un comportamiento que pone en tensión los derechos que tiene cada persona respecto de su propio desarrollo. En ese sentido, actualmente, hacerse cargo de otro se interpreta como una desigualdad generacional, en la que la persona que tiene que cuidar a sus padres debe dejar de estudiar o trabajar, lo que limita sus posibilidades de desarrollo personal. Asimismo, las personas mayores que viven con sus hijos, nietos u otros parientes también consideran vulnerados sus derechos en la medida en que, en muchos casos, son los encargados del sostenimiento económico de la familia, así como de la responsabilidad de los nietos que pasa de ser una opción a una obligación. De esta manera, la desigualdad intergeneracional es tanto para los hijos como para los padres (Jaramillo, 2017).

Este artículo muestra cómo las acciones de la política nacional siguen orientadas por la idea de una familia que tanto en su extensión como en su composición y funcionamiento ha cambiado. El principal problema de esto radica en que la transformación y ruptura de las solidaridades tradicionales fundadas en el parentesco no han sido compensadas por el desarrollo de solidaridades formales/institucionales y comunitarias fundadas en los derechos. Esto refleja que el reconocimiento político no se ha podido materializar en acciones que promuevan nuevos vínculos orientados a la integración y cohesión social y, por consiguiente, al bienestar individual y colectivo de la población mayor. Una consecuencia de esta tensión entre la política y la acción es la sobrecarga de la familia, que debe seguir respondiendo y superando las situaciones de adversidad relacionadas con el envejecimiento (salud, vivienda, alimentación, bienestar) sin tener los apoyos formales/institucionales y comunitarios necesarios. Esto aumenta los riesgos y la incidencia de problemas asociados a sentimientos de aislamiento, como la depresión y el suicidio, que vienen registrando un incremento en la población mayor. Las solidaridades han sido históricamente las relaciones sociales que favorecen los sentimientos de unidad e integración, fundamentales para la supervivencia, reproducción y conservación de las sociedades humanas. En este sentido, los arreglos residenciales también son un indicador de integración y cohesión social (Jaramillo, 2017).

El principal referente del contexto institucional colombiano en relación con el envejecimiento, la vejez y los arreglos residenciales es la Política Pública Social para el Envejecimiento y la Vejez, la cual establece los lineamientos y las acciones para los próximos diez años. De ahí la importancia de revisar la política nacional y su contexto regional y mundial, ya que de ello depende la oferta pública orientada a las demandas 
de los hogares independientes en la vejez que, por sus condiciones socioeconómicas mencionadas, requieren una atención especial por parte del Estado.

En ese sentido, el objetivo de este artículo es conocer parte de las circunstancias de la institucionalidad pública para el envejecimiento, la vejez y los arreglos residenciales, con el fin de reflexionar acerca de las condiciones institucionales del país para enfrentar las demandas sociales que surgen a partir de los cambios residenciales en la vejez. Esto se hace a partir de tres puntos. El primero es la descripción del contexto general que se hace por medio de la recopilación de las asambleas mundiales y conferencias regionales que se han hecho sobre envejecimiento y vejez y su relación con el hogar y el arreglo residencial. Con la revisión del contexto mundial y regional, se identifica la conceptualización y el reconocimiento que tiene la problemática, es decir, su posición en las agendas públicas, así como la coherencia entre los instrumentos internacionales, regionales y nacionales, con el fin de observar la fuerza de los compromisos políticos y su influencia en las acciones locales. El segundo corresponde a los avances legislativos y políticos del país en relación con el envejecimiento y la vejez, a partir de los cuales se busca identificar el proceso general de construcción de la Política Nacional de Envejecimiento y Vejez y su relación con los arreglos residenciales. El último punto tiene que ver con los avances y las contradicciones de la implementación de dicha política, que son una aproximación a las acciones concretas territoriales que definen las respuestas específicas que el Estado les está ofreciendo a los distintos arreglos residenciales de las personas mayores. De tal manera, se puede considerar si el país tiene la infraestructura institucional necesaria para afrontar el cambio residencial y crear condiciones propicias para la adaptación de la sociedad a esta nueva condición de desarrollo que es el envejecimiento demográfico. Es adecuado precisar que, aunque los dos primeros apartados hacen una recopilación de información similar a un estado de la cuestión, no es su objetivo. La reconstrucción de los avances normativos tiene el propósito de mostrar el amplio reconocimiento mundial y regional del problema de los arreglos residenciales y la urgencia de establecer modelos de solidaridad modernos orientados, en especial, por las instituciones y comunidades (Jaramillo, 2017).

Es importante señalar que a lo largo del artículo se mencionan los asuntos relacionados con familia y hogar, conceptos que se encuentran vinculados porque en la mayoría de los casos coinciden como forma concreta de organización residencial. Es decir, el hogar o arreglo residencial no se refiere solo a la composición y estructura del grupo, sino a las relaciones de solidaridad que lo constituyen y hacen posible históricamente. La variabilidad de la composición y estructura de los hogares se relaciona con las formas de solidaridad y apoyo históricas, las cuales varían en el tiempo. Por ejemplo, los hogares unipersonales existen gracias a los procesos de urbanización e institucionalización de las sociedades modernas, que crearon las condiciones de posibilidad para que las 
personas pudieran sostenerse a sí mismas por las relaciones modernas de trabajo y acceder a servicios de salud y apoyo a través de instituciones especializadas en la oferta de servicios sociales. Así, la protección social del Estado fue reemplazando varias de las funciones que cumplía la familia en el orden rural, y que no hacían que fuera posible vivir solo, debido a que la supervivencia, la reproducción y las alternativas de desarrollo estaban centralizadas en la vida familiar y a que no se diferenciaba lo doméstico de lo productivo. El surgimiento de esta diferenciación establece un nuevo orden social, en el que las relaciones de dependencia se transforman, permiten que los sujetos se organicen de una forma independiente y obtengan la seguridad económica y social a partir del trabajo remunerado y el acceso a las instituciones de protección social. Sin embargo, estas circunstancias son distintas según las condiciones económicas, sociales y culturales de cada población. En este sentido, se hace necesario estudiar la situación de cada sociedad para comprender las relaciones de solidaridad y las condiciones de autonomía que sostienen los distintos tipos de hogar de las personas mayores. En las sociedades que han tenido procesos de institucionalización desiguales y lentos como la colombiana, es posible que sean las familias y sus solidaridades tradicionales las que continúan soportando las necesidades de los distintos tipos de arreglo residencial, lo que aumenta no solo la precariedad de la vida de los ancianos, sino la de todas las generaciones que hacen parte de los grupos familiares (Jaramillo, 2017).

Así como la familia y los arreglos residenciales aparecen relacionados, la vejez y el envejecimiento también se encuentran mutuamente vinculados en los distintos instrumentos políticos. La razón es que el incremento de la proporción de los ancianos y de su duración de vida son algunos de los principales indicadores del envejecimiento demográfico. En este sentido, la mayoría de las acciones se plantean en especial para esta población, aunque suponen un trabajo con todos los grupos de edad, ya que constituyen las futuras generaciones de viejos, y su proceso de envejecimiento se da a lo largo de toda la trayectoria vital. A pesar de las diferencias conceptuales entre envejecimiento demográfico e individual y vejez, hasta el momento en las políticas, los planes y las acciones son parte de un mismo campo (Jaramillo, 2017).

\section{Asambleas mundiales}

En 1978, la Asamblea General de las Naciones Unidas reconoce el crecimiento de la población de personas mayores de 60 años como uno de los principales resultados de los avances en la longevidad humana, por lo que se decide formular y aplicar políticas a nivel internacional, regional y nacional para reafirmar la aplicación total e íntegra de la Declaración Universal de los Derechos Humanos, así como la defensa de la calidad de vida, entendida como las condiciones de posibilidad para que las personas mayores logren su plena realización y disminuyan los efectos negativos del envejecimiento. Para esto, se 
convoca, en 1982, una asamblea mundial sobre el envejecimiento, en la que se formuló un plan de acción internacional sobre el envejecimiento orientado a garantizar las condiciones económicas y sociales de las personas mayores, así como su aporte al avance de sus países. Se concibe como parte de otros esfuerzos internacionales como la Declaración Universal de los Derechos Humanos, los Pactos Internacionales de Derechos Humanos, la Declaración sobre el Establecimiento de un Nuevo Orden Económico Internacional, la Estrategia Internacional del Desarrollo para el Tercer Decenio de las Naciones Unidas para el Desarrollo y las resoluciones del Segundo Decenio para el Desarme, así como los planes mundiales de acción aprobados internacionalmente: Población (Bucarest, 1974), Año Internacional de la Mujer (México, 1975; Copenhague, 1980), Atención Primaria de Salud (Ginebra, 1978), HÁBITAT (Vancouver, 1976), Medio Humano (Estocolmo, 1972), Ciencia y Tecnología para el Desarrollo (Viena, 1978), Combatir el Racismo y Discriminación Racial (Ginebra,1978), Cooperación Técnica entre los Países en Desarrollo (Buenos Aires, 1978) y la Reforma Agraria y Desarrollo Rural (Roma, 1979) (Asamblea Mundial sobre el Envejecimiento. 26 julio a 6 de agosto de 1982 Viena, Austria).

Uno de los catorce principios del Plan de Acción se orienta hacia el amparo de la familia, que considera la relevancia de su función para la sociedad, así como su composición intergeneracional: "La familia, en sus diversas formas y estructuras, es una unidad fundamental de la sociedad que vincula las generaciones, y deberá mantenerse, fortalecerse y protegerse de conformidad con las tradiciones y costumbres de cada país”. De igual forma, la familia y el sistema de parentesco se concibe como uno de los principales medios que brindan satisfacción personal a las personas mayores, por lo que se recomienda su consideración en la elaboración de las políticas y medidas orientadas a su bienestar. Se destaca la importancia de ampliar los esfuerzos del sector público para asumir las relaciones de dependencia y cuidado que tradicionalmente han estado a cargo de la familia, pero que, con el aumento de las personas mayores y las transformaciones de las familias grandes, no lo podrán seguir haciendo (Asamblea Mundial sobre el Envejecimiento. 26 julio a 6 de agosto de 1982 Viena, Austria).

Además de ser un principio y una recomendación para la formulación de las políticas y medidas, la familia fue considerada en el plan como una de las siete 4 "Esferas de preocupación de las personas de edad", que responde a los principales cambios observados en la familia. Los dos primeros son la nueva composición multigeneracional y la modificación de las funciones tradicionales de las mujeres como cuidadoras de las personas mayores, debido a su participación en la fuerza laboral. En ese sentido, se elaboran las siguientes recomendaciones:

1. Los gobiernos deberán promover las políticas sociales que alienten el mantenimiento de la solidaridad familiar entre negociaciones, con la participación de todos los miembros 
de la familia. Deberá también subrayarse a todos los niveles el papel y la aportación de las organizaciones no gubernamentales en el fortalecimiento de la familia como unidad. 2. El respaldo apropiado del sector más amplio de la comunidad, disponible cuándo y dónde sea necesario, puede representar una diferencia trascendental respecto a la voluntad y capacidad de las familias de seguir cuidando a los parientes de edad avanzada. En la planificación y prestación de servicios se deberá tener plenamente en cuenta las necesidades de quienes prestan tales cuidados. (Asamblea Mundial sobre el Envejecimiento. 26 julio a 6 de agosto de 1982 Viena, Austria)

Un tercer cambio que se considera es la transformación del lugar y la posición tradicional de las personas mayores en el hogar, así como la tendencia hacia que la familia ya no sea la única fuente de apoyo de las personas mayores. $\mathrm{Al}$ respecto, se proponen tres recomendaciones:

1. Las formas de preservar la función esencial de la familia y la dignidad, la situación y la seguridad de las personas de edad teniendo en cuenta todos los acontecimientos internos e internacionales que puedan influir en esta situación de seguridad, son cuestiones que merecen cuidadosa consideración y medidas, tanto por parte de los gobiernos como de las organizaciones no gubernamentales. Habida cuenta del mayor número de mujeres de edad y de la proporción relativamente mayor de viudas que de viudos en todo el mundo, deberá prestarse particular consideración a las necesidades y funciones especiales a este grupo. 2. Se insta a los gobiernos a que en sus actividades de planificación y desarrollo adopten un criterio integrado respecto a la edad y la familia en el que se reconozcan las necesidades y características especiales de las personas de más edad y de sus familias. Las personas de más edad deben ser incluidas en los procesos de adopción de decisiones gubernamentales y de otra índole, entre otras, en las esferas política, social, cultural y educativa y debe alentarse a los hijos a que mantengan a sus padres. 3. Deberá alentarse a los gobiernos y a los órganos no gubernamentales a que establezcan servicios sociales en apoyo de toda la familia cuando existan personas de edad en el hogar y a que apliquen medidas en especial destinadas a las familias de bajos ingresos que deseen mantener en el hogar a las personas de edad avanzada. (Asamblea Mundial sobre el Envejecimiento. 26 julio a 6 de agosto de 1982 Viena, Austria)

En 1991, la Asamblea de las Naciones Unidas establece con la Resolución 46 cinco principios a favor de la población mayor: independencia, participación, cuidado, ${ }^{5}$ realización personal y dignidad. Para garantizar estos principios, se consideró necesario el desarrollo de políticas y servicios que brindaran el soporte y la protección social necesaria. En este sentido, la articulación entre las solidaridades formales e 
informales, es decir, la relación entre el Estado, la sociedad y la familia, se reconoce como un factor clave a fin de crear las condiciones adecuadas para la garantía de los derechos humanos y la libertad de las personas de edad (Asamblea General, Cuadragésimo sexto periodo de sesiones 1991).

En 2002, se realizó una Segunda Asamblea en Madrid (España). En ella se elaboró una declaración política y un nuevo plan de acción, que se centró en tres orientaciones prioritarias: "Las personas de edad y el desarrollo, el fomento de la salud y el bienestar en la vejez y la creación de entornos emancipadores y propicios”. En esta ocasión, los gobiernos aceptaron vincular el envejecimiento a los acuerdos celebrados en las conferencias y cumbres realizadas por Organización de las Naciones Unidas (ONU) durante la década de los noventa, que tenían como objetivo avanzar en los asuntos relacionados con el desarrollo social, económico y de los derechos humanos. En la declaración política, los representantes de los 159 gobiernos que participaron reconocieron el envejecimiento de la población del siglo XXI como un desafío importante que requiere el esfuerzo conjunto de los Estados para favorecer el crecimiento de sociedades humanas maduras, integradas en contextos democráticos y multigeneracionales, que garanticen el bienestar económico y social de las personas de edad. La familia se consideró como uno de los temas centrales asociados a las metas, los objetivos y el compromisos del plan: "El reconocimiento de la importancia decisiva que tienen para el desarrollo social las familias y la interdependencia, la solidaridad y la reciprocidad entre las generaciones”. En los artículos 13 y 15, se resalta la participación y función de las familias en la asistencia social de las personas de edad:

(13) Destacamos la responsabilidad primordial de los gobiernos de promover y prestar servicios sociales básicos y de facilitar el acceso a ellos, teniendo presentes las necesidades específicas de las personas de edad. A tal fin, tenemos que trabajar con las autoridades locales, la sociedad civil, incluidas las organizaciones no gubernamentales, el sector privado, los voluntarios y las organizaciones de voluntarios, las propias personas de edad y las asociaciones de personas de edad y las que se dedican a ellas, así como con las familias y las comunidades. (15) Reconocemos lo importante que es la función de las familias, los voluntarios, las comunidades, las organizaciones de personas de edad y otras organizaciones de base comunitaria para prestar a las personas de edad apoyo y cuidados no estructurados, complementarios a los que proporcionan los gobiernos. (ONU, 2003)

Las tres orientaciones prioritarias del plan consideran a la familia y el hogar dentro de sus cuestiones, objetivos y medidas (véase tabla 1). En "Orientación prioritaria I, La personas de edad y el desarrollo”, se advierte acerca de los riesgos de exclusión que tienen las personas de edad, en relación con los avances sociales, económicos y 
tecnológicos, en especial los concernientes a los procesos de migración, urbanización, reducción de los tamaños de las familias y el desarrollo de tecnologías orientadas hacia la individualización, los cuales pueden amenazar su participación en la sociedad y la conservación de las fuentes tradicionales de apoyo, como la familia y la comunidad. Para garantizar la permanente integración y adaptación de las personas de edad a los procesos de evolución social, y viceversa, se proponen ocho cuestiones, con objetivos y medidas.

Las cuestiones propuestas entienden a la familia como un ambiente de reconocimiento, equidad y solidaridad para las personas de edad, por lo que recomiendan acciones en tres sentidos. El primero ${ }^{6}$ trata de la valoración de los aportes sociales, económicos y de conocimiento de las personas mayores a sus familias, comunidades y países. En ellos se destacan sus contribuciones en la atención y el cuidado de sus parientes, el trabajo no remunerado del hogar y la transmisión de sus conocimientos, así como su capacidad de liderazgo en asuntos de educación, comunicación y solución de conflictos. El segundo ${ }^{7}$ tiene que ver con el equilibrio entre los sexos tanto en la vida doméstica como laboral. Los riesgos de dependencia y pobreza de las mujeres en su vejez pueden ser mayores de los de los hombres, debido a que su vida laboral está mediada por la desigualdad de salarios y por las responsabilidades de atención familiar, por lo que se considera importante ampliar las oportunidades en educación a lo largo de toda la vida. $Y$ el tercero ${ }^{8}$ se refiere a la transformación de las redes de apoyo tradicional de las familias extendidas. El éxodo de los jóvenes adultos de las áreas rurales y la escasa infraestructura de apoyo en las ciudades disminuyen las posibilidades de soporte financiero y social de las personas mayores y aumentan sus posibilidades de exclusión. En este sentido, la conservación de solidaridades intergeneracionales en la familia y su ampliación hacia las comunidades y las naciones resulta importante. Esto contribuye al mantenimiento de la cohesión social y los aportes financieros, educativos y de cuidado que pueden brindar entre las distintas generaciones, más allá de las rupturas de los vínculos solidarios tradicionales. Asimismo, el estudio de los arreglos residenciales se considera relevante para fortalecer la solidaridad y reciprocidad entre las generaciones, respetando las distintas formas de vida residencial (ONU, 2003). 


\section{Tabla 1}

\section{Orientación prioritaria I de la Declaración Política y Plan de} Acción Internacional de Madrid sobre el Envejecimiento según las cuestiones, objetivos y medidas orientados hacia la familia

Las personas de edad y el desarrollo: "Las personas de edad deben ser participantes plenas en el proceso de desarrollo y compartir también los beneficios que reporte. No debe negarse a nadie la posibilidad de beneficiarse del desarrollo. Los efectos del envejecimiento de la población sobre el desarrollo socioeconómico de la sociedad, combinados con los cambios sociales y económicos que están teniendo lugar en todos los países, crean la necesidad de adoptar medidas urgentes para garantizar la constante integración y habilitación de las personas de edad. Además, la migración, la urbanización, el cambio de la familia extendida hacia familias más pequeñas y móviles, la falta de acceso a tecnologías que promueven la independencia y otros cambios socioeconómicos pueden marginar a las personas de edad y apartarlas de la corriente principal del desarrollo, privarlas de las funciones económicas y sociales significativas y debilitar sus fuentes tradicionales de apoyo".

\begin{tabular}{|c|c|c|}
\hline Cuestión & Objetivo & Medida \\
\hline $\begin{array}{l}\text { Participación activa en la } \\
\text { sociedad y en el desarrollo. }\end{array}$ & $\begin{array}{l}\text { "Reconocimiento de } \\
\text { la contribución social, } \\
\text { cultural, económica y } \\
\text { política de las personas de } \\
\text { edad". }\end{array}$ & $\begin{array}{l}\text { "Reconocer, alentar y apoyar la } \\
\text { contribución de las personas de } \\
\text { edad a la familia, la comunidad y la } \\
\text { economía". }\end{array}$ \\
\hline $\begin{array}{l}\text { El empleo y el } \\
\text { envejecimiento de la } \\
\text { fuerza de trabajo. }\end{array}$ & $\begin{array}{l}\text { "Brindar oportunidades } \\
\text { de empleo a todas las } \\
\text { personas de edad que } \\
\text { deseen trabajar". }\end{array}$ & $\begin{array}{l}\text { "Reconocer y tomar en cuenta las } \\
\text { obligaciones que tiene un número } \\
\text { cada vez mayor de trabajadores de } \\
\text { atender a las personas de edad } \\
\text { de su familia, a las personas con } \\
\text { discapacidades y a quienes padecen } \\
\text { enfermedades crónicas, incluido el } \\
\text { VIH/sida, formulando, entre otras } \\
\text { cosas, políticas favorables para las } \\
\text { familias y que tengan en cuenta los } \\
\text { aspectos de género, encaminadas a } \\
\text { reconciliar las obligaciones laborales } \\
\text { y de prestación de atención". }\end{array}$ \\
\hline $\begin{array}{l}\text { Desarrollo rural, migración } \\
\text { y urbanización. }\end{array}$ & $\begin{array}{l}\text { "Integración de los } \\
\text { migrantes de edad } \\
\text { avanzada en sus nuevas } \\
\text { comunidades". } \\
\end{array}$ & $\begin{array}{l}\text { "Ayudar a las familias a compartir } \\
\text { sus alojamientos con los familiares } \\
\text { de edad que así lo deseen". }\end{array}$ \\
\hline $\begin{array}{l}\text { Acceso al conocimiento, } \\
\text { la educación y la } \\
\text { capacitación. }\end{array}$ & $\begin{array}{l}\text { Utilización plena de } \\
\text { las posibilidades y los } \\
\text { conocimientos de las } \\
\text { personas de todas las } \\
\text { edades, reconociendo } \\
\text { los beneficios derivados } \\
\text { de la mayor experiencia } \\
\text { adquirida con la edad. }\end{array}$ & $\begin{array}{l}\text { "Alentar y apoyar las actividades } \\
\text { tradicionales y no tradicionales de } \\
\text { asistencia mutua intergeneracional } \\
\text { dentro de la familia, la vecindad y } \\
\text { la comunidad, aplicando una clara } \\
\text { perspectiva de género". }\end{array}$ \\
\hline
\end{tabular}




\begin{tabular}{|l|l|l|}
\hline $\begin{array}{l}\text { Solidaridad } \\
\text { intergeneracional. }\end{array}$ & $\begin{array}{l}\text { Fortalecer la solidaridad } \\
\text { mediante la equidad y } \\
\text { reciprocidad entre las } \\
\text { generaciones. }\end{array}$ & $\begin{array}{l}\text { "Emprender investigaciones sobre } \\
\text { las ventajas y desventajas de los } \\
\text { distintos arreglos en materia de } \\
\text { vivienda de las personas de edad, } \\
\text { con inclusión de la residencia en } \\
\text { común con los familiares y las } \\
\text { formas de vida independiente, en } \\
\text { diferentes culturas y contextos". }\end{array}$ \\
\hline $\begin{array}{l}\text { Erradicación de la pobreza. } \\
\text { ingresos, protección } \\
\text { social /seguridad social y } \\
\text { prevención de la pobreza. }\end{array}$ & $\begin{array}{l}\text { No se menciona la familia. } \\
\text { familia. }\end{array}$ & \begin{tabular}{l} 
No se menciona la familia. \\
\hline Situaciones de emergencia.
\end{tabular} \\
$\begin{array}{l}\text { No senciona la familia. } \\
\text { de las personas de } \\
\text { edad a los alimentos, la } \\
\text { vivienda y la atención } \\
\text { médica y otros servicios } \\
\text { durante y después de los } \\
\text { desastres naturales y otras } \\
\text { situaciones de emergencia } \\
\text { humanitaria". }\end{array}$ & $\begin{array}{l}\text { "1) Reconocer que los refugiados } \\
\text { de edad de orígenes culturales } \\
\text { distintos que envejecen en entornos } \\
\text { nuevos y no familiares suelen estar } \\
\text { especialmente necesitados de } \\
\text { redes sociales y apoyo adicional, } \\
\text { y procurar garantizar que tengan } \\
\text { acceso físico a esos servicios; } 2) \\
\text { ayudar a las personas de edad a } \\
\text { restablecer sus vínculos familiares } \\
\text { y sociales y a superar el estrés } \\
\text { postraumático; y 3) reconocer } \\
\text { el potencial de las personas de } \\
\text { edad como líderes de la familia } \\
\text { y la comunidad en materia de } \\
\text { educación, comunicación y solución } \\
\text { de conflictos". }\end{array}$ \\
\hline
\end{tabular}

Fuente: ONU (2003).

En “Orientación prioritaria II, El fomento de la salud y el bienestar en la vejez", la familia se reconoce, junto con los gobiernos y las organizaciones no gubernamentales, como uno de los principales agentes que brindan apoyo a los individuos, para que conserven una forma de vida saludable, entendida como bienestar físico, mental y social. La responsabilidad de llegar a la vejez en condiciones de bienestar depende tanto del esfuerzo personal como de entornos que faciliten y apoyen el autocuidado a lo largo de la vida. Se señala que, en los países en desarrollo, la familia y la comunidad son principalmente los que ofrecen la asistencia a las personas que la necesitan, y que lo deseable es que las personas puedan envejecer en sus hogares. Sin embargo, la no remuneración de la atención familiar genera nuevos problemas económicos y sociales: 
Hoy se reconoce, en particular, el costo que representa para la mujer, que sigue prestando la mayor parte de la asistencia no estructurada. Las mujeres que la prestan deben soportar el costo financiero de una contribución reducida a los regímenes de pensiones debida a sus ausencias del mercado laboral, a la pérdida de oportunidades de ascenso y a sus menores ingresos. También deben afrontar el costo físico y emocional de las tensiones resultantes de intentar compaginar las obligaciones laborales con las domésticas. Esa situación reviste una dificultad especial para las mujeres con hijos que deben atender también a personas de edad. (ONU, 2003)

Además de la atención, las familias tienen un papel importante en la prevención, el soporte y el tratamiento de las personas. En ese sentido, aparte de ser una fuente de soporte para el individuo, constituyen un aliado para los gobiernos en la formación de entornos adecuados. Sin embargo, no se establecen objetivos y medidas que permitan identificar las formas en las que los gobiernos pueden habilitar tanto a las personas de edad como a sus familiares para fomentar la salud y el bienestar a lo largo de la vida individual y familiar. Los objetivos y las medidas propuestos se centran en tres aspectos: 1) la prevención de lesiones involuntarias asociadas a la movilidad peatonal, las caídas y los accidentes en el hogar; 2) los efectos del VIH/sida en las personas mayores y en sus familias; y 3) el desarrollo de programas de atención para enfrentar los problemas de salud mental, que incluyen la formación de los familiares y profesionales que cuidan a los enfermos. A pesar de que la familia cumple un papel muy importante en la prevención y atención en salud, se explica que sus servicios no pueden reemplazar un sistema de salud eficaz (véase tabla 2). 


\section{Tabla 2}

\section{Orientación prioritaria II de la Declaración Política y Plan de Acción Internacional de Madrid sobre el Envejecimiento}

El fomento de la salud y el bienestar en la vejez: la Organización Mundial de la Salud define la salud como un estado de completo bienestar físico, mental y social, y no meramente como la ausencia de enfermedades o padecimientos. Llegar a la vejez gozando de buena salud y bienestar requiere un esfuerzo personal durante toda la vida y un entorno en el que ese esfuerzo pueda tener éxito. La responsabilidad de las personas consiste en llevar un modo de vida saludable, mientras que la de los gobiernos en crear un entorno favorable a la salud y al bienestar, incluso, en la vejez. Tanto por razones humanitarias como económicas, es necesario brindar a las personas de edad el mismo acceso a la atención preventiva y curativa y a la rehabilitación de que gozan otros grupos. Al mismo tiempo, debe disponerse de servicios de salud concebidos para atender las necesidades especiales de las personas de edad, teniendo en cuenta la introducción de la medicina geriátrica en los planes de estudio universitarios y sistemas de atención de la salud pertinentes, según corresponda. Además de los gobiernos, hay otros agentes importantes, en particular las organizaciones no gubernamentales y las familias, que proporcionan apoyo a los individuos para que mantengan un modo de vida saludable al tiempo que cooperan estrechamente con los gobiernos en la creación de un entorno propicio.

\begin{tabular}{|l|l|l|}
\hline $\begin{array}{l}\text { El fomento de la salud y } \\
\text { la vida. }\end{array}$ & $\begin{array}{l}\text { Elaboración de políticas } \\
\text { para prevenir la mala } \\
\text { salud entre las personas } \\
\text { de edad. }\end{array}$ & $\begin{array}{l}\text { Prevenir las lesiones involuntarias } \\
\text { promoviendo una mejor } \\
\text { comprensión de sus causas, } \\
\text { adoptando medidas de protección } \\
\text { de los peatones, ejecutando } \\
\text { programas para prevenir las caídas, } \\
\text { reduciendo al mínimo los riesgos, } \\
\text { incluido el de incendios, en el hogar, } \\
\text { y proporcionando asesoramiento en } \\
\text { cuestiones de seguridad. }\end{array}$ \\
\hline $\begin{array}{l}\text { Acceso universal y } \\
\text { equitativo a los servicios } \\
\text { de atención de la salud. }\end{array}$ & No se menciona la familia. & No se menciona la familia. \\
\hline $\begin{array}{l}\text { Las personas de edad y el } \\
\text { VIH/sida. }\end{array}$ & $\begin{array}{l}\text { Mejorar la evaluación } \\
\text { de los efectos del VIH/ } \\
\text { SIDA sobre la salud } \\
\text { de las personas de } \\
\text { edad, tanto para las } \\
\text { infectadas comp para } \\
\text { las que atienden a } \\
\text { familiares infectados o } \\
\text { sobrevivientes. }\end{array}$ & No se menciona la familia. \\
\hline $\begin{array}{l}\text { Capacitación de los } \\
\text { proveedores de servicios } \\
\text { de salud y de los } \\
\text { profesionales de la salud. } \\
\text { familia. }\end{array}$ & No se menciona a la familia. \\
\hline
\end{tabular}




\begin{tabular}{|l|l|l|}
\hline $\begin{array}{l}\text { Necesidades relacionadas } \\
\text { con la salud mental de las } \\
\text { personas de edad. }\end{array}$ & $\begin{array}{l}\text { Desarrollo de servicios } \\
\text { amplios de atención } \\
\text { de la salud mental que } \\
\text { comprendan desde la } \\
\text { prevención hasta la } \\
\text { intervención temprana, la } \\
\text { prestación de servicios de } \\
\text { tratamiento y la gestión } \\
\text { de los problemas de salud } \\
\text { mental de las personas } \\
\text { de edad. }\end{array}$ & $\begin{array}{l}\text { a la autoayuda y prestar servicios } \\
\text { de cuidados temporales para los } \\
\text { pacientes, sus familias y otras } \\
\text { personas que presten asistencia; 2) } \\
\text { ofrecer programas para ayudar a las } \\
\text { personas que padecen la enfermedad } \\
\text { de Alzheimer o enfermedades } \\
\text { mentales debidas a otras causas } \\
\text { de demencia a vivir en sus hogares } \\
\text { hasta tanto sea posible y a subvenir } \\
\text { a sus necesidades de salud. }\end{array}$ \\
\hline $\begin{array}{l}\text { Las personas de edad con } \\
\text { discapacidad. }\end{array}$ & No se menciona la familia. & No se menciona a la familia. \\
\hline
\end{tabular}

Fuente: ONU (2003).

En “Orientación prioritaria III, Creación de un entorno propicio y favorable”, la vivienda y el entorno se reconocen como condiciones fundamentales para el bienestar de las personas de edad. Se resaltan los problemas de cobertura de servicios y vivienda, en los contextos urbanos que enfrentan un envejecimiento demográfico acelerado, mientras que en las áreas rurales preocupa la soledad de las personas mayores que ya no cuentan con contextos familiares tradicionales, ni con recursos económicos e infraestructura de transporte público adecuados. De igual forma, es posible que las personas de edad no puedan seguir sosteniendo sus casas, luego de que sus hijos se han ido o su cónyuge ha muerto. Los objetivos y las medidas propuestos se dirigen hacia la conservación de la integración familiar, respetando las preferencias de las personas mayores desde el punto de vista de la forma residencial que desean. También se busca ofrecer sistemas de apoyo social estructurado y no estructurado a la familia, con énfasis en las mujeres de edad (ONU, 2003) (véase tabla 3).

\section{Tabla 3 \\ Orientación prioritaria III, Creación de un entorno propicio y favorable de la Declaración Política y Plan de Acción Internacional de Madrid sobre el Envejecimiento}

\footnotetext{
La creación de un entorno propicio y favorable para las personas de edad, la vivienda y el entorno son particularmente importantes debido a factores como la accesibilidad y la seguridad, la carga financiera que supone mantener un hogar y la importante seguridad emocional y psicológica que brinda el hogar. Es un hecho reconocido que una vivienda satisfactoria puede ser beneficiosa para la salud y el bienestar. También es importante que, siempre que sea posible, las personas de edad tengan la posibilidad de elegir debidamente el lugar donde quieren vivir, factor que es preciso incorporar a las políticas y los programas.
} 


\begin{tabular}{|c|c|c|}
\hline $\begin{array}{l}\text { La vivienda y las } \\
\text { condiciones de vida }\end{array}$ & \begin{tabular}{|l|} 
Promover el \\
envejecimiento en la \\
comunidad en que se \\
ha vivido, teniendo \\
debidamente en \\
cuenta las preferencias \\
personales y las \\
posibilidades en materia \\
de vivienda asequible \\
para las personas de \\
edad. \\
\end{tabular} & $\begin{array}{l}\text { 1) Coordinar los esfuerzos multisectoriales } \\
\text { que se realicen para apoyar el } \\
\text { mantenimiento de la integración de las } \\
\text { personas de edad con sus familias y } \\
\text { comunidades y 2) proporcionar a las } \\
\text { personas de edad, a sus familias y a las } \\
\text { personas que las cuidan información y } \\
\text { asesoramiento, de modo oportuno y eficaz, } \\
\text { sobre las opciones de que disponen en } \\
\text { materia de vivienda. }\end{array}$ \\
\hline $\begin{array}{l}\text { Asistencia y apoyo a las } \\
\text { personas que prestan } \\
\text { asistencia }\end{array}$ & $\begin{array}{l}\text { 1) Ofrecer asistencia y } \\
\text { servicios continuados, } \\
\text { de diversas fuentes, } \\
\text { a las personas de } \\
\text { edad, y apoyo a las } \\
\text { personas que prestan } \\
\text { asistencia; y 2) apoyo } \\
\text { a la función asistencial } \\
\text { que desempeñan las } \\
\text { personas de edad, } \\
\text { particularmente las } \\
\text { mujeres de edad. }\end{array}$ & $\begin{array}{l}\text { Obetivo 1: 1) Tomar medidas para } \\
\text { proporcionar asistencia comunitaria y } \\
\text { apoyo a la atención familiar; } 2 \text {. Organizar } \\
\text { sistemas de apoyo social, estructurados } \\
\text { y no estructurados, a fin de potenciar la } \\
\text { capacidad de las familias para cuidar a las } \\
\text { personas de edad en el ámbito familiar, } \\
\text { inclusive, en particular, la prestación de } \\
\text { apoyo y servicios a largo plazo al número } \\
\text { creciente de personas de edad que } \\
\text { tienen una salud delicada; } 3 \text { ) promover } \\
\text { la prestación de asistencia comunitaria y } \\
\text { el apoyo a la atención familiar tomando } \\
\text { en consideración la distribución equitativa } \\
\text { entre las mujeres y los hombres de } \\
\text { las responsabilidades de los cuidados } \\
\text { mediante medidas para lograr una mejor } \\
\text { compaginación de la vida laboral y familiar. } \\
\text { Objetivo } 2: \text { 1. Estimular la prestación de } \\
\text { apoyo social, los servicios para aliviar la } \\
\text { carga de trabajo, el asesoramiento y la } \\
\text { información con destino a las personas } \\
\text { de edad que se ocupan de atender a } \\
\text { otros y a los familiares bajo su cuidado; } \\
\text { 2) es necesario que los profesionales } \\
\text { reconozcan los riesgos de abandono, } \\
\text { maltrato o violencia por parte de los } \\
\text { encargados, profesionales o no, de atender } \\
\text { a las personas de edad en el hogar o en } \\
\text { contextos comunitarios o institucionales. }\end{array}$ \\
\hline
\end{tabular}

Fuente: ONU (2003).

En 2011, el secretario general de la ONU presentó un informe de Seguimiento regional de la Segunda Asamblea Mundial sobre el Envejecimiento, el cual se centró en las circunstancias de los derechos humanos de las personas de edad alrededor del mundo. 
Este muestra la adopción de políticas y programas que introducen el envejecimiento de la población en los asuntos de salud, seguridad social y bienestar, así como la aprobación de planes de acción nacionales sobre envejecimiento. Respecto de la familia, se menciona que hay diversas percepciones de la función que las personas mayores tienen en ellas. De esta manera, algunos gobiernos buscan replantear las representaciones sociales acerca de las personas de edad y el empleo, las formas de atención y las solidaridades intergeneracionales; otros intentan encontrar que las políticas promuevan los principios de actividad y autonomía; y los demás insisten en que la fuente primaria de atención y apoyo de las personas de edad es la familia, por lo que se resalta la importancia de los lazos familiares. Estas perspectivas consideran adecuado la creación de redes que incluyan distintos niveles de apoyo (privado, voluntario, comunitario) con el propósito de lograr un buen funcionamiento del sistema (ONU, 2011).

Dentro de las principales preocupaciones identificadas, las mujeres se destacan por su vulnerabilidad. La acumulación de las desigualdades educativas y laborales a lo largo de sus vidas se refleja en mayores probabilidades de ser pobres en comparación con los hombres:

Además, las mujeres de edad con frecuencia asumen mayores responsabilidades en lo referente a la atención de la familia, al tiempo que se enfrentan a condiciones de trabajo inflexibles, edades de jubilación obligatorias y pensiones y otros beneficios sociales insuficientes, todo lo cual las deja, a ellas y a las personas a su cuidado, en una situación de extrema vulnerabilidad. Sin duda, el envejecimiento, los problemas relacionados con los derechos humanos que plantea y su feminización introducen un cambio sin precedentes en el tejido social de todas las sociedades, con consecuencias de gran alcance. (ONU, 2011)

Según este informe, se destacan cuatro problemas como los más frecuentes alrededor del mundo: 1) la pobreza y la precariedad de las condiciones de vida, 2) la discriminación por motivos de edad, 3) la violencia y el maltrato y 4) la falta de medidas, mecanismos y servicios especiales. En el primer problema, se señala que las personas mayores siguen siendo cabeza de familia y cuidadores de sus nietos y otros familiares, a pesar de tener menores ingresos en comparación con otros segmentos de la población. Esto también se explica por la disminución del apoyo de la familia a las personas de edad debido a su nuclearización, lo cual ha hecho que en algunos países se incremente el número de instituciones geriátricas. Asimismo, los movimientos migratorios dejan a los mayores solos, a cargo de sí mismos y de otros familiares dependientes como los nietos, sin contar con una fuente de ingreso que reconozca su labor como cuidadores y les permita dar cuenta de sus necesidades y las de sus parientes. El segundo problema destaca la escasez de oportunidades de acceso a fuentes de ingreso para las personas de edad. El tercer problema se 
refiere al abuso físico, emocional o sexual de las personas de edad, que es compartido por todos los países. La familia es uno de los escenarios en los que se llevan a cabo el maltrato. Por último, se menciona la escasez de referencias explícitas a la edad en los instrumentos internacionales de derechos humanos; respecto de la familia solo existe la "Convención Internacional sobre la protección de los derechos de todos los trabajadores migratorios y de sus familiares, incluye la 'edad' en la enumeración de los motivos de discriminación (art. 7)". Asimismo, los mecanismos de derechos humanos reconocen a las personas mayores como un grupo vulnerable que necesita disposiciones particulares de protección:

En concreto, el 16 2) de la Convención sobre los derechos de las personas con discapacidad exige una asistencia y un apoyo "que tengan en cuenta [...] la edad" para las personas con discapacidad y sus familiares a fin de prevenir los casos de explotación, violencia y abuso, reconociendo así las situaciones particulares en que las personas de edad son vulnerables. (ONU, 2011)

También se recuerda que una parte de las recomendaciones realizadas en el Plan de Acción Internacional de Viena sobre el Envejecimiento (Asamblea Mundial sobre el Envejecimiento 26 julio a 6 de agosto de 1982 Viena, Austria), que señala que las políticas nacionales deben orientarse hacia la permanencia de las personas de edad en sus propios hogares, asegurar su integración y proporcionar su movilidad y comunicación a través de medios de transporte adecuados (ONU, 2011).

Dentro de las respuestas nacionales a los problemas planteados y relacionados con los derechos humanos, se menciona el reconocimiento constitucional generalizado de los principios de igualdad y no discriminación de las personas de edad, así como la descentralización de los servicios y las políticas que faciliten una respuesta adecuada a nivel local. Se considera que los gobiernos están avanzando en la recopilación de estadísticas y datos básicos que apoyen la formulación de planes y sistemas de evaluación. Uno de los intereses es el conocimiento de los hogares polivalentes. Respecto de las respuestas nacionales, la familia se menciona en cuatro ocasiones: 1) violencia y maltrato, se destaca la ausencia de disposiciones particulares para combatir el abuso y maltrato de las familias a las mujeres que han quedado viudas; 2) salud, parte de los problemas que tienen las personas de edad para recibir una atención oportuna por cuenta de los servicios de salud es que los familiares se demoran en llevar a los mayores a los centros médicos porque atribuyen los síntomas de la enfermedad al envejecimiento; 3) falta de acceso a la atención de la salud, debido a las largas distancias e insuficiente infraestructura de transporte, en especial en las zonas rurales, así como a la falta de educación en salud pública, entre otras; 4) seguridad y protección social, que se refiere a los aumentos en la cobertura y el acceso universal a las pensiones por parte de las personas de edad, 
que tiene un efecto positivo no solo en la reducción general de la pobreza, sino en sus hogares, porque garantiza el acceso regular a los alimentos y recursos básicos que mejoran los niveles de subsistencia (ONU, 2011).

\section{Conferencias regionales en América Latina y el Caribe}

En 2002, se realizó la Reunión de expertos en redes sociales de apoyo a las personas adultas mayores: rol del Estado, la familia y la comunidad como parte del proceso preparatorio de la primera conferencia regional intergubernamental sobre envejecimiento. El objetivo de la reunión era colectivizar el conocimiento sobre el tema y brindar recomendaciones generales para la construcción de una estrategia regional de envejecimiento que facilite la formulación de políticas y programas sobre redes de apoyo social en personas de edad. Las orientaciones se basaron en el Declaración Política y Plan de Acción Internacional de Madrid sobre el Envejecimiento, así como en otros instrumentos internacionales ${ }^{9}$ (ONU, 2003).

El objetivo general de las recomendaciones fue "fortalecer las redes de apoyo social de las personas mayores para mejorar su calidad de vida y potenciar su desarrollo como sujetos de derechos". Los principios de las sugerencias fueron el reconocimiento de las personas de edad como sujetos de derechos; la conservación y valoración de su independencia y autonomía; el reconocimiento de las interrelaciones entre las personas mayores y sus contextos familiar, comunitario y societal; el reconocimiento del envejecimiento como un proceso que sucede a lo largo de la vida y que requiere de la solidaridad intergeneracional; y la articulación y coordinación de las acciones a nivel nacional, regional y local. A partir de ellos, las recomendaciones se estructuraron en cuatro áreas, en las que se destaca la relevancia de las fuentes de apoyo en la disminución de las desigualdades sociales (véase tabla 4).

\section{Tabla 4}

\section{Áreas de planificación e intervención de las redes de apoyo social}

\begin{tabular}{|l|l|l|}
\hline \multicolumn{1}{|c|}{ Área } & \multicolumn{1}{c|}{ Objetivos } & \multicolumn{1}{c|}{ Estrategias } \\
\hline Personas mayores como & Habilitar a las personas & 1) Creación de condiciones \\
sujetos de derechos. & mayores como sujetos & favorables para el \\
& de derechos y promover & empoderamiento de las \\
& el reconocimiento de su & personas mayores, 2) \\
& contribución a la sociedad. & promoción de la asociatividad \\
& & y participación de las \\
& & personas mayores y 3) \\
& & promoción de la solidaridad \\
intergeneracional.
\end{tabular}




\begin{tabular}{|l|l|l|}
\hline $\begin{array}{l}\text { Disponibilidad de los sistemas } \\
\text { de apoyo social de las } \\
\text { personas mayores. }\end{array}$ & $\begin{array}{l}\text { Aumentar la disponibilidad de } \\
\text { los sistemas de apoyo social } \\
\text { de las personas mayores. }\end{array}$ & $\begin{array}{l}\text { 1) Desarrollo de iniciativas } \\
\text { para la complementariedad } \\
\text { de los sistemas formales } \\
\text { e informales de apoyo, } \\
\text { 2) creación de entornos } \\
\text { favorables que permitan } \\
\text { la sostenibilidad de los } \\
\text { sistemas de apoyo social de } \\
\text { las personas mayores y 3) } \\
\text { adecuación de los sistemas de } \\
\text { apoyo a las necesidades de } \\
\text { las personas mayores. }\end{array}$ \\
\hline $\begin{array}{l}\text { Igualdad de los sistemas de } \\
\text { apoyo social de las personas } \\
\text { mayores. }\end{array}$ & $\begin{array}{l}\text { Disminuir las desigualdades } \\
\text { de los sistemas de apoyo } \\
\text { social de las personas } \\
\text { mayores. }\end{array}$ & $\begin{array}{l}\text { 1) Reducción de las } \\
\text { diferencias de acceso y } \\
\text { beneficio de las fuentes } \\
\text { formales e informales de } \\
\text { apoyo y 2) desarrollo de un } \\
\text { papel proactivo del Estado } \\
\text { en la disminución de las } \\
\text { desigualdades de apoyo } \\
\text { social. }\end{array}$ \\
\hline Mecanismos de seguimiento. & $\begin{array}{l}\text { Desarrollo de indicadores } \\
\text { fesarrollar mecanismos } \\
\text { implementación de estas } \\
\text { recomendaciones. }\end{array}$ & $\begin{array}{l}\text { yedición sobre redes de } \\
\text { apoyo social de personas } \\
\text { mayores. }\end{array}$ \\
\hline
\end{tabular}

Fuente: Cepal (2002).

Posteriormente, en la Conferencia Regional Intergubernamental sobre Envejecimiento realizada en Santiago en 2003, se asumió la Estrategia Regional de Implementación para América Latina y el Caribe del Plan de Acción Internacional de Madrid sobre el Envejecimiento. En este encuentro, se establecieron las prioridades y los objetivos de la región. Dentro de las consideraciones generales, se menciona que el envejecimiento de la región tiene unos retos particulares, relacionados, por una parte, con la velocidad del envejecimiento, que es mayor a la observada en los países desarrollados, y por otra, con unas condiciones sociales y económicas desiguales, acompañadas de una alta participación laboral en el mercado informal y un escaso desarrollo institucional que se refleja en una baja cobertura de la seguridad social. En este contexto, la reducción de los tamaños de las familias puede aumentar el riesgo de que las generaciones más jóvenes no tengan los recursos suficientes para apoyar a las generaciones viejas. Y si desde el Estado no se ofrece un soporte que compense, se puede agudizar los efectos negativos del envejecimiento, en especial para las mujeres. Sin embargo, con una mayor inversión en capital humano, las nuevas generaciones pueden acceder a condiciones que les permitan 
mantener el apoyo familiar, ya que la disminución de la fecundidad también puede ser una oportunidad para que la carga de dependencia de los niños y los jóvenes disminuya.

Dentro de las propuestas de la Estrategia Regional de Implementación para América Latina y el Caribe, se insiste en la necesidad de crear condiciones adecuadas para articular la plena participación de las personas mayores en la sociedad, con el fin de favorecer su empoderamiento como grupo social y fortalecer el ejercicio de una ciudadanía activa. Para esto, se recomienda: 1) apoyar la elaboración de estudios en los que se cuantifique el aporte de las personas de edad a sus familias, comunidades y sociedad en general; 2) reconocer la carga que tienen las familias de las personas con VIH/ sida y, en especial, las mujeres mayores que, por lo general, son las cuidadoras en los hogares. Se sugiere que estas cargas deben crear medidas que reconozcan, no solo el rol de la mujer en la provisión de cuidados, sino la responsabilidad compartida con los hombres; 3) la atención de las personas dependientes, en general, es asumida por una sola persona, lo que es excesivo si se considera que esta también se hace cargo de otros asuntos en el hogar (Cepal, 2003).

Posteriormente, se realizó un segundo encuentro, la Declaración de Brasilia. Segunda Conferencia regional intergubernamental sobre envejecimiento en América Latina y el Caribe: hacia una sociedad para todas las edades y de protección social basada en derechos. Brasilia, 4 al 6 de diciembre de 2007, cuyo propósito fue establecer los elementos más importantes para aplicar a América Latina y el Caribe el Plan de Acción Internacional de Madrid sobre el Envejecimiento. En dicha declaración, la familia y el hogar se mencionan para destacar la relevancia de examinar el impacto de las migraciones en la dinámica del envejecimiento. Los lugares de origen, tránsito y destino, así como en los migrantes, sus familias, comunidades y los desarrollos sociales y económicos. De igual forma, recomendaron la prestación de apoyo psicosocial a los familiares de las personas de edad que tienen enfermedades en condición terminal. También promovieron la realización de iniciativas para adecuar las viviendas a las nuevas formas de organización residencial como los hogares multigeneracionales y unipersonales en los que se hallan personas mayores, así como facilitar que las personas puedan envejecer en sus hogares contando con medidas de soporte a las familias, en especial a las mujeres en los asuntos domésticos. Además, se planteó la necesidad de crear marcos legales y formas de supervisión para la protección de los derechos humanos y las libertades fundamentales de las personas mayores, tanto en los hogares institucionalizados como particulares. Asimismo, se espera que se formulen y cumplan leyes y programas de prevención de abuso, maltrato y violencia contras las personas de edad (Cepal, 2008).

En 2008, se efectúo la Primera Reunión de seguimiento de la Declaración de Brasilia, cuyo trabajo era elaborar recomendaciones acerca de un proyecto de convención de derechos de las personas de edad, las consideraciones prácticas para la creación de la 
convención y de un relator especial de los derechos de las personas mayores (párrs. 25 y 26 de la Declaración de Brasilia). En dicha reunión, se hizo énfasis en que las políticas públicas se deben basar en conceptos de derechos y en la incorporación de la sociedad civil en los debates de derechos humanos. Esto implica pasar de un paradigma asistencial en los asuntos de vejez a uno con enfoque de derechos. También se destacó la importancia de tener un documento jurídicamente vinculante para proteger los derechos de las personas mayores. No se mencionó de forma directa la familia y el hogar (Cepal, 2008).

En 2009, se llevó a acabo la Segunda Reunión de seguimiento de la Declaración de Brasilia, en Buenos Aires. Allí se llamó la atención respecto de que el Plan de Acción Internacional de Madrid sobre el Envejecimiento tiene vacíos en su implementación normativa, y que es una herramienta orientada hacia la prestación de servicios más que a la garantía de derechos. Entre los temas prioritarios, se consideró el derecho de las personas mayores a vivir en la forma residencial que deseen, "igualdad de derechos de las personas que viven en residencias de larga estadía, el derecho a la privacidad, derecho a envejecer en casa, contar con cuidadores domiciliarios”, así como la relevancia de que esta convención no sea un documento adaptado de otros textos internacionales, sino que corresponda a los principales problemas regionales como que "la seguridad económica es un tema pendiente en Latinoamérica. Hay personas mayores que no acceden a la seguridad social y obtienen ingresos a través del trabajo informal y la ayuda familiar”. Allí el problema de la seguridad económica no atenta solo contra los derechos fundamentales de la persona de edad, sino de los ingresos del grupo familiar.

En los lineamientos para la elaboración de una convención, se declara el interés por promover y desarrollar una cultura del envejecimiento en la que todas las personas (países, familias, ciudadanos, jóvenes, niños) contribuyan a nuevos comportamientos de respeto por las personas mayores, por ejemplo, promoviendo la escucha o en la movilidad disminuyendo la velocidad o dando el paso. También la necesidad de aumentar las oportunidades de acceso a la educación, en universidades y ambientes culturales, entre otros. Por otra parte, se sugiere que se consideren las circunstancias de maltrato en la familia, ya que, en ocasiones, este no se denuncia. En este caso, se hace una mayor referencia al tema de la institucionalización de las personas mayores sin su consentimiento, que se relaciona directamente con la violación de la libertad. Asimismo, se recomienda empoderar a las personas mayores para que participen en la toma de decisiones. Y brindar la protección social adecuada tanto a la persona de edad como a su familia. A continuación, se presentan los seis lineamientos que incluyen directamente a la familia:

- Concientización: necesidad de concientizar a toda la sociedad, inclusive a las familias, sobre las condiciones de las personas de edad y fomentar el respeto por los derechos y por la dignidad de las personas de edad. 
- Prevención contra la tortura y los tratos o penas crueles, inhumanas o degradantes: las personas de edad tienen derecho a estar libres de recibir tratamientos inhumanos, violentos, aterrorizantes, humillantes, despectivos, vejatorios o forzados.

- Prevención contra la explotación, la violencia, el abuso y los malos tratos: las personas de edad deben ser protegidas, tanto dentro como fuera de su hogar, contra todas las formas de explotación, violencia, incluso la violencia de género, física, psicológica y sexual, abuso y malos tratos, en sus formas institucional, económica, familiar y social, haciendo hincapié en la condición general de la capacidad de las personas de edad y de la incapacidad solo como excepción.

- Respecto de la privacidad: ninguna persona de edad, cualquiera sea su lugar de residencia o tipo de morada, deberá ser sujeta a interferencia arbitraria o ilegal en su privacidad, familia, domicilio o correspondencia u otro tipo de comunicación, en ataques ilícitos a su honra y reputación, en especial las personas de edad institucionalizadas.

- Respeto del hogar y de la diversidad de formas de familia: las personas de edad tienen derecho a la participación en la vida familiar y comunitaria. Se deberán desplegar todos los esfuerzos necesarios para apoyar, proteger y fortalecer a las familias y ayudarlas, de acuerdo con los valores culturales de cada sociedad, a atender a sus familiares mayores dependientes o a su cargo.

- Nivel de vida y protección social adecuados: las personas de edad tienen derecho a un nivel de vida adecuado, así como para sus familias, incluso alimentación, agua, vivienda, vestuario y atención de salud adecuada, así como el mejoramiento constante de sus condiciones de vida, mediante la provisión de ingresos, el apoyo de sus familias y de la comunidad y su propia autosuficiencia (Cepal, 2009).

Al final de la propuesta de contenidos, se postula el enfoque del curso de vida como fundamentación de esta convención. Tener en cuenta que la vida es un continuo, desde que se nace hasta que se muere. En ese sentido, al mencionar la calidad de vida y los asuntos más relevantes, se debería priorizar a las personas y a las familias. La incorporación de la familia permitiría abordar la problemática de una forma compleja con mayor difusión del asunto de vejez. Asimismo, se advierte acerca de la importancia de conceptualizar claramente lo que se define como familia (Cepal, 2009).

En 2011, se realizó un nuevo seguimiento que mostró los principales problemas para el avance de la institucionalización del envejecimiento en la región. La mayor dificultad es la desarticulación de los programas y planes nacionales sectoriales, que atienden situaciones específicas, sin integrar la diversidad de las condiciones en las que envejecen las personas. A esto se suma la existencia de una sociedad civil desunida, que no ejerce su poder político. Y la baja incidencia política de las personas de edad, considerando su bajo acceso en la toma de decisiones en todos los niveles (Cepal, 2011). 
Por otra parte, las condiciones de vida de las personas de edad no muestran una mejora efectiva, que refleje las reformas a los sistemas previsionales. Tampoco existen los marcos legales suficientes para la operacionalización de las medidas sugeridas a favor de las personas de edad que garanticen "educación, salud, redes de servicios, prevención de la violencia, formación continua de recursos humanos y financieros en todos los casos, lo cual depende de la voluntad política a nivel de los poderes ejecutivo y legislativo". Una de las reflexiones finales del encuentro señala: “Desde nuestras actividades y experiencias de vida diaria, podemos afirmar que envejecer en América Latina y el Caribe todavía significa para la mayoría de las personas vivir en condiciones de pobreza, discriminación, inseguridad e incertidumbre" (Cepal, 2011).

$\mathrm{Al}$ final del evento, se priorizaron acciones para mejorar las institucionalidades públicas, de forma que la región pueda responder al acelerado cambio demográfico que provoca el envejecimiento. Para esto, se sugiere que los servicios sociales y de cuidado trabajen en la autonomía, en una imagen de la vejez que considere su heterogeneidad, en la integración de los sistemas médicos y sociales, así como en responder eficazmente a las necesidades de cuidados de las personas de edad que se encuentren en situación de dependencia (Cepal, 2011).

En 2012, se realizó la Tercera Conferencia Regional Intergubernamental sobre Envejecimiento en América Latina y el Caribe. La Cepal presentó la síntesis del informe sobre la aplicación de la Estrategia Regional de Implementación para América Latina y el Caribe del Plan de Acción Internacional de Madrid sobre el Envejecimiento y la Declaración de Brasilia. En ella se menciona que el reto más importante para América Latina y el Caribe es la ampliación del acceso a la protección social, entendida como las intervenciones de las entidades públicas y privadas en el manejo de los riesgos y las necesidades de los hogares y los individuos. En este sentido, se propone la integración de la seguridad de ingresos, la atención básica de salud y los servicios sociales para la autonomía como la forma de reducir las brechas de protección y desplegar capacidades. Con esto, se espera que las personas de edad y las familias superen las condiciones de desigualdad que surgen a partir del acceso diferenciado a las pensiones, ya que esto depende de las posiciones que históricamente han tenido las personas en el mercado laboral y no del ejercicio de un derecho en condiciones de igualdad (Cepal, 2012).

La perspectiva de la igualdad entiende los cambios demográficos como aspectos fundamentales para la creación de oportunidades y la redefinición de las funciones de la familia, el mercado y el Estado. Para esto, es necesario que la protección social se adecúe a los cambios demográficos, con el fin de responder eficazmente a los procesos de cambio y nuevas demandas sociales que resultan de los nuevos órdenes sociodemográficos. El hecho de que la mayoría de las personas de edad no cuente con una pensión que garantice una seguridad económica y que las condiciones de continuidad o ingreso al mercado 
laboral sean desiguales y precarias hace que la familia tenga que cargar con los riesgos económicos de esta etapa. Esto se expresa tanto en las transferencias informales de dinero como en los servicios de atención y cuidado, en especial en salud, que en el mercado tienen un costo elevado y no son de fácil acceso para las personas de edad de la región. Además, los cambios en las estructuras familiares como producto de la transición demográfica, no solo han aumentado la participación de hogares con personas de edad, sino que su forma tradicional de familia extendida se ha diversificado con hogares de tamaños más pequeños, en los que se experimenta una sobrecarga de demandas económicas y de cuidado, que, sin el apoyo necesario del Estado, pueden afectar negativamente, no solo el bienestar de las personas de edad, sino de la familia. Se calcula que hacia 2063 , por cada niño, habrá al menos dos mayores, lo que es un desafío para los gobiernos, el mercado, la familia y la sociedad para adaptarse a un cambio duradero en sus formas de organización, así como en la elaboración y gestión de las políticas. Es necesario y prioritario que los rectores de las políticas públicas de los países consideren, como ya se mencionó, la redefinición del rol que desempeñan el Estado, el sector privado y la familia en la protección social de la vejez, así como la progresiva debilidad de las redes de apoyo familiar y la falta de servicios sociales que aseguren una vida digna para las personas de edad y sus familias (Cepal, 2012).

\section{Política social para la vejez en Colombia}

\section{Aspectos normativos}

Los antecedentes normativos de la política social para la vejez en Colombia se iniciaron en la década de los setenta con la Ley 29/1975, de 25 de septiembre, mediante la cual se buscaba establecer la protección de los ancianos considerados en estado de indigencia y sin familia, y la ejecución del sistema de pensiones de vejez creado a partir de la Ley 90/1946, de 26 de diciembre, reglamentado por el Decreto 3041/1966, de 19 de diciembre. Las bases conceptuales de estas normas reflejan una reducción de la ancianidad a las condiciones materiales y de carencia, que deja de lado sus relaciones y contexto social (Arrubla, 2015).

Posteriormente, en la Constitución Política de 1991, se estableció, en el capítulo 2 "De los derechos sociales, económicos y culturales", artículo 46, la obligatoriedad del Estado, la sociedad y la familia de concurrir para la protección y la asistencia de las personas de la tercera edad y promover su integración a la vida activa y comunitaria, señalando que "el Estado les garantizará los servicios de la seguridad social integral y el subsidio alimentario en caso de indigencia”.

En 2012, el país presentó un informe de avance general respecto de la implementación de la Declaración de Brasilia en América Latina y el Caribe. Allí se expusieron los resultados obtenidos hasta ese momento: 
I) Definición de la Política Nacional de Envejecimiento y Vejez liderada por el Ministerio de Salud y Protección Social; II) Establecimiento de la Metodología de Participación Social de y para las personas mayores - MIPSAN, de obligatoriedad en su aplicación para la co-financiación de proyectos que desarrollan los departamentos, distritos y municipios en el marco de esta Política Nacional; III) Programa Nacional de Protección Social al Adulto Mayor - PPSAM, consistente en subsidios monetarios, beneficiando en los últimos años a 627.428 personas mayores en extrema pobreza y situación de vulnerabilidad como personas en situación de desplazamiento, personas con discapacidad, víctimas de la violencia, personas en situación de indigencia o abandono y población de personas mayores indígenas en los resguardos; IV) Programa Nacional de Alimentación para el Adulto Mayor - PNAAM “Juan Luis Londoño de la Cuesta”, constituido como una alternativa para ofrecer servicios básicos de alimentación a las personas más pobres y vulnerables, con el fin de contribuir a mitigar su situación, con una cobertura similar al PPSAM, de casi medio millón de personas mayores en situación de vulnerabilidad. El programa en los primeros años de funcionamiento tuvo una cobertura del 2003 al 2010 de 417.230 personas mayores. En el 2011 pasó a 221.953 personas mayores y de 214.933 en el 2012. En este mismo año, se modificó el programa al pasar de ración alimentaria a subsidio monetario.

Otros programas que se han venido desarrollando son entre otros, los siguientes: I) Programa Nuevo Comienzo, "otro motivo para vivir", del Departamento Administrativo del Deporte, La Recreación, La Actividad Física y el Aprovechamiento del Tiempo Libre COLDEPORTES. Se desarrolla en conjunción con los departamentos, distritos y municipios, dirigido a las personas mayores. Es de rescatar que tiene cobertura nacional y participan las personas mayores incluidas en el Sisben 1 y 2; II) El Programa de capacitación a las personas mayores en las Tecnologías de la Información y las Comunicaciones - TICS, liderado por el Ministerio de las Tecnologías de la Información y las comunicaciones el cual también cuenta con cobertura nacional; III) Formación para el trabajo, generación de ingresos para jóvenes y la ley del primer empleo, son políticas que promueven en la población joven el acceso a mejores condiciones de vida que les permite envejecer activa y productivamente, así como varias normas específicas para la protección de los derechos de las personas mayores ${ }^{10}$ que se relacionan de una forma directa o indirecta con la población de edad. (Cepal, 2012a)

La Ley 1251/2008, de 27 de noviembre y la Política Nacional de Envejecimiento Humano y Vejez son los dos instrumentos nacionales con mayor influencia en las acciones que se desarrollan como parte del proceso de institucionalización. Esta ley establece las normas para garantizar los derechos de las personas de edad. En ella se dispone la expedición de dicha política en la que le proporciona el marco y define las áreas de intervención que debe considerar. Dentro de sus principios, se reconoce la corresponsabilidad que tienen el Estado, la familia y la sociedad civil en la participación 
e integración de los adultos mayores a la sociedad, así como en la garantía del acceso a beneficios con el propósito de compensar las desigualdades sociales y territoriales y el ofrecimiento de apoyo y ayuda a las personas mayores que se encuentren en condición de vulnerabilidad. La familia se menciona en varias partes de esta ley, tanto como uno de los agentes de apoyo a las personas de edad como sujeto de derecho y protección social.

En el artículo 6 de la Ley 1251/2008, de 27 de noviembre, se mencionan los deberes del Estado, la sociedad civil y la familia. En ellos se reconoce la obligación del Estado de exigir que la familia garantice la alimentación de las personas de edad y de la sociedad civil por generar acciones de solidaridad hacia la población que se encuentra en estado de vulnerabilidad. Esto reduce significativamente la amplia perspectiva de la protección social presentada en los instrumentos internacionales y regionales, así como el derecho de todas las personas de edad a gozar de la solidaridad de la sociedad civil, deber que se focaliza en la población vulnerable. Por su parte, la familia está a cargo de una gran cantidad de deberes que, junto con los del adulto mayor, revelan una sobrecarga de funciones en la familia y las personas de edad, que continúa reproduciendo el rol tradicional de los parientes como protectores sociales, sin considerar las nuevas condiciones sociodemográficas que impiden sostener el modelo social de comienzos del siglo XX. Los deberes propuestos en dicha ley no revelan las corresponsabilidades que tienen el Estado, la sociedad civil, la familia y las personas mayores. Se observa un desequilibrio entre deberes, que refleja la ausencia de la definición clara de los límites entre las responsabilidades de cada agente, así como la comprensión del sistema de interrelaciones entre los distintos actores y su influencia en la adecuada distribución de las cargas económicas y sociales. A continuación, se presentan los deberes que según esta ley tienen los distintos actores, en relación directa con la familia y las personas de edad:

1. Del Estado: [...] k. Generar acciones y sanciones que exijan el cumplimiento de las obligaciones alimentarias a las familias que desprotejan a los adultos mayores sin perjuicio de lo establecido en la normatividad vigente.

2. De la sociedad civil: Todos los deberes son hacia la persona de edad. En ninguno se menciona a la familia o el hogar.

3. De la Familia: a) Reconocer y fortalecer las habilidades, competencias, destrezas y conocimientos del adulto mayor; b) Respetar y generar espacios donde se promuevan los derechos de los adultos mayores; c) Propiciar al adulto mayor de un ambiente de amor, respeto, reconocimiento y ayuda; d) Brindar un entorno que satisfaga las necesidades básicas para mantener una adecuada nutrición, salud, desarrollo físico, psíquico, psicomotor, emocional y afectivo; e) Establecer espacios de relación intergeneracional entre los miembros de la familia; f) Proteger al adulto mayor de todo acto o 
hecho que atente o vulnere los derechos, vida, integridad, honra y bienes; g) Vincular al adulto mayor en los servicios de seguridad social y sistema de salud; h) Proporcionar al adulto mayor espacios de recreación, cultura y deporte; i) Brindar apoyo y ayuda especial al adulto mayor en estado de discapacidad; j) Respetar las vivencias, cultura, tradiciones y expresiones de los adultos mayores; k) Promover la participación de los adultos mayores en la discusión, diseño, formulación y ejecución de políticas, planes, programas y proyectos de interés para la familia, la sociedad y el Estado; 1) Aceptar el ejercicio de la autonomía y la autorrealización personal de los adultos mayores; $\mathrm{m}$ ) Atender las necesidades Psicoactivas del adulto mayor cuando se encuentre en condiciones de institucionalización, en ningún caso podrán dejarlo abandonado y a cargo de la institución sin mantener los lazos familiares.

4. Del Adulto Mayor: a) Desarrollar actividades de autocuidado de su cuerpo, mente y del entorno; b). Integrar sus hábitos saludables y de actividad física; c) Hacer uso racional de los medicamentos siguiendo las recomendaciones médicas prescritas; d) Participar activamente en las actividades deportivas, recreativas, culturales que le permitan envejecer sanamente, de planeación de políticas públicas y programas que se diseñen a favor de este grupo de población en lo local; e) Promover la participación en redes de apoyo social que beneficien a la población en especial aquellas que se encuentran en condiciones de extrema pobreza y de vulnerabilidad social, así como vigilar el cumplimiento de las políticas sociales y de asistencia social que se desarrollen en su identidad territorial; f) Propender por su propio bienestar y crear condiciones que le permitan reducir su nivel de dependencia familiar y estatal, haciéndolo autosuficiente y desarrollando sus capacidades y potencialidades; g) Proporcionar información verídica y legal de sus condiciones sociales y económicas.

Por su parte, los artículos 8 y 10 se refieren a las directrices de la Política Nacional de Envejecimiento y Vejez. Respecto de la familia, se hace un énfasis en el apoyo de los cuidadores de las personas de edad. Esto resulta contradictorio frente a los deberes, ya que ni el Estado ni la sociedad civil tienen un deber explícito por brindar ese apoyo. Esto puede dejar este último a un acto voluntario o de caridad de las personas que lo consideren adecuado, y no como un asunto de deberes y derechos. De igual forma, dicha política está encargada de promover la organización de la familia y las interrelaciones entre sus integrantes:

Art 8: a) Promocionar una cultura de respeto al adulto mayor dentro de la sociedad y la familia; b) Fortalecer redes sociales de apoyo mediante el comportamiento solidario y la corresponsabilidad entre la familia, la sociedad y el Estado, así como la promoción, apoyo y protección a los cuidadores de los adultos mayores en situación de dependencia en casa. 
Art. 10: La Política Nacional de Envejecimiento y Vejez incluirá medidas tendientes a promover la organización de la familia e involucrarla en el desarrollo integral de los adultos mayores que la conforman propendiendo igualmente por la debida interrelación entre sus miembros.

En el artículo 17, se establecen las áreas de intervención que se deben tener en cuenta para la elaboración del plan nacional. En ellas se menciona la familia y su comunidad como parte del sistema de bienestar y protección del que hace parte la persona de edad. En esta parte de la ley, hay una particularidad en relación con las directrices, que es la educación y su función en las transformaciones personales y colectivas que implica el proceso de envejecimiento humano:

Protección a la salud y bienestar social. Los adultos mayores tienen derecho a la protección integral de la salud y el deber de participar en la promoción y defensa de la salud propia, así como la de su familia y su comunidad.

Educación, cultura y recreación. [...] e. Lograr una mejor calidad y expectativas de vida personal, familiar y social a través de acciones educativas y participativas que permitan crear conciencia de la dignidad humana y formar actitudes positivas y respetuosas frente a la vejez y al envejecimiento como aporte a la Sociedad; [...] f. Contribuir a la educación integral de esta población permitiéndole elaborar proyectos de vida acordes con su edad y expectativas de vida que los ayuden a asumir roles en la vida familiar y social.

Entorno físico y social favorable. Corresponde al Estado, a través de sus entidades del orden Nacional, Departamental, Distrital y Municipal de conformidad con el ámbito de sus competencias, a las instituciones públicas y privadas garantizar a los adultos mayores condiciones óptimas para que el entorno físico sea acorde con sus necesidades, [...]; c. Generar estrategias para permitir el acceso a proyectos de vivienda de interés social que ofrezcan igual oportunidad a las parejas compuestas por los adultos mayores, solas o jefes de familia.

Respecto de la participación de las personas de edad en sus familias, comunidades y país, esta ley establece el Consejo Nacional del Adulto Mayor. En el punto 2 del artículo 27, uno de sus fines es "2. Apoyar y fortalecer la participación de la comunidad, la familia y el adulto mayor en las acciones necesarias para su desarrollo físico, psíquico, económico, social y político”.

Otros marcos normativos que se han elaborado a favor de la población mayor son la Ley 1091/2006, de 8 de septiembre; la Ley 1171/2007, de 7 de diciembre; el Decreto 3771/2007, de 1 de octubre; la Ley 1276/2009, de 5 de enero; y la Ley 1315/2009, de 13 
de julio; todos ellos orientados en especial a la población en estado de vulnerabilidad, y centrados en los servicios asistenciales de alimentación, estadía y salud.

\section{Actualización de la política}

Política Nacional de Envejecimiento y Vejez 2007-2019, cuyos objetivos generales son:

- Incidir de manera activa, a nivel intersectorial y territorial, sobre las condiciones de desarrollo social, económico y cultural de los individuos, la familia y la sociedad, como medio para propiciar que los viejos de hoy y del futuro alcancen una vejez digna, saludable e integrada, en el marco de la promoción, prevención y restitución de los derechos humanos.

- Crear condiciones para el envejecimiento de la población, entendido como el derecho de toda la población a una vida digna, larga y saludable, reconociendo la trascendencia de la corresponsabilidad individual, familiar y social en este proceso.

La realización de los objetivos se propone a partir de cuatro ejes: 1) promoción y garantía de los derechos humanos de las personas mayores, que busca cumplir con los compromisos internacionales y constitucionales para la garantía del ejercicio efectivo de los derechos; 2) protección social integral, ${ }^{11}$ que debe reducir la vulnerabilidad económica y social e incrementar la calidad de vida de las personas de edad; 3) envejecimiento activo, que pretende crear las condiciones de seguridad social integral para que la población adquiera hábitos que favorezcan su autonomía, salud y productividad a lo largo de la vida; 4) formación de recurso humano e investigación, con el que se espera generar conocimiento acerca del envejecimiento y la vejez que facilite la gestión individual y colectiva del proceso de envejecimiento del país. A cada uno de estos ejes le corresponden distintas líneas estratégicas, de acción y metas que pretenden reducir las condiciones de vulnerabilidad de las personas de edad e incrementar su calidad de vida (Ministerio de la Protección Social, 2007-2019).

Política Colombiana de Envejecimiento Humano y Vejez 2014-2024, ${ }^{12}$ en la que se conservan los objetivos y los ejes del primer texto, pero se modifica la conceptualización del envejecimiento y la vejez. La primera versión de la política se fundamenta en cuatro aspectos conceptuales. El primero se refiere al envejecimiento biológico, entendido como la consecuencia universal de la acción del tiempo en los seres vivos. Su relación con los desarrollos científicos y tecnológicos que han influido en la reducción de la mortalidad y el aumento de la esperanza de vida han provocado el envejecimiento demográfico del país. El segundo destaca la relevancia de los derechos humanos en el reconocimiento de las personas de edad como sujetos especiales de derecho. El tercero propone el envejecimiento activo, definido 
como el proceso de adquisición de hábitos saludables a través del curso de vida, como condición necesaria para que las futuras generaciones envejezcan con autonomía, productividad y reconocimiento. Y el último corresponde a la protección social integral, entendido como el conjunto de políticas públicas orientadas al manejo social del riesgo, que tiene el objetivo de disminuir vulnerabilidades y mejorar la calidad de vida de las personas de edad.

En 2014, se incluyeron dos aspectos más: la longevidad y la organización del cuidado. Ambos hacen parte de uno de los tres pilares básicos de la protección social, propuestos por la Cepal en 2012. El énfasis en el cuidado refleja la situación de las dependencias en la región, las cuales van a aumentar debido al alto número de niños, el incremento de las personas mayores y de las enfermedades de largo plazo asociadas al aumento de la longevidad. En este sentido, la política destaca la responsabilidad colectiva que se tiene respecto de la dependencia y el cuidado, así como de las formas de prevención y atención:

Transitar hacia la construcción de la dependencia y el cuidado como un asunto de responsabilidad colectiva, que debe ser sostenido mediante prestaciones y servicios que maximicen la autonomía y el bienestar de las familias y los individuos en el marco de los sistemas de protección social. Las respuestas públicas para la atención de esta problemática han de concebirse como una extensión lógica del quehacer estatal, que impone ciertas obligaciones inmediatas con respecto a los que precisan ayuda y quienes la brindan. (Cepal, 2012)

El cuidado es la acción social dirigida a garantizar la supervivencia social y orgánica de las personas que carecen o han perdido la autonomía personal y que necesitan ayuda de otros para realizar los actos esenciales de la vida diaria (Huenchuan, 2013). En particular, durante los últimos años, ha venido creciendo la importancia de los cuidados a largo plazo durante la vejez, que incluyen servicios de atención de las necesidades tanto médicas como no médicas de las personas adultas mayores que no pueden cuidar de sí mismas durante largos periodos. Los cuidados a largo plazo adoptan dos modalidades: atención domiciliaria e institucional. Por atención domiciliaria se entiende, en general, los servicios prestados por profesionales en casa de la persona mayor, mientras que por atención institucional el alojamiento y el cuidado de una persona en una entidad especializada (Naciones Unidas, 2010, citado por Cepal, 2009).

Además, se requiere promover la combinación de los servicios disponibles y ampliar la gama de servicios de cuidado de modo que ofrezcan respuestas adecuadas a cada situación particular. Resulta fundamental entonces fortalecer la promoción de la salud tanto como el mantenimiento y la mejora de la capacidad funcional de las personas adultas mayores, desde el autocuidado y el cuidado familiar hasta el cuidado comunitario y el cuidado institucional, con la claridad suficiente para asumir que la institucionalización constituye la última alternativa, y deberá ser la menos utilizada. 
Los aspectos conceptuales de la Política Nacional de Envejecimiento y Vejez se sustentan en el reconocimiento de los derechos humanos de las personas adultas mayores, su integración comunitaria y la superación de desigualdades sociales y de género dirigidas al fortalecimiento de la ciudadanía y las prácticas democratizadoras a lo largo del curso de la vida, con énfasis en la vejez (Ministerio de Salud y la Protección Social [MinSalud], 2014).

Otra novedad de la actualización de la política es la consideración del curso de vida humana en lugar del envejecimiento biológico, así como la comprensión del envejecimiento activo como una forma de vida que favorece a lo largo de la vida la acumulación de oportunidades para alcanzar una madurez digna. Estos avances conceptuales buscan ampliar la comprensión de la complejidad del envejecimiento humano como un proceso multidimensional y heterogéneo, que depende de las interacciones entre los cambios biológicos y psicológicos de las personas a lo largo de su vida y las condiciones sociales, económicas e históricas de sus entornos (MinSalud, 2014). El enfoque del curso de vida no es algo reciente en el país, sino que desde la década de los noventa se realizaron algunas actividades académicas como el Simposio Internacional sobre Ciclo de Vida, Educación y Envejecimiento y, en 2002, apareció la revista Ciclo de Vida (Anónimo 5, comunicación personal, junio de 2015). Este enfoque no es un asunto nuevo, sino que su inclusión en la agenda pública ha sido un proceso lento, si se considera que hace más de treinta años los organismos internacionales ya habían identificado la importancia de avanzar en la conceptualización y comprensión de la vejez:

El Plan de Acción Internacional de Viena sobre el Envejecimiento señala que el envejecimiento es un proceso que dura toda la vida, y que debemos prepararnos como tal para las etapas posteriores. Tenemos una mirada diferente, ya no en el modelo de psicología del desarrollo por etapas, sino de transcurso o curso de vida. Entonces, cuando es por etapas, las edades separan más en lo biológico, [por el contrario, las] teorías explicativas homogeneizan a la gente, mientras que en el transcurso de vida son teorías integradoras, la edad es un parámetro, no es algo decisivo. Se tiene en cuenta la multifactorialidad, nosotros no somos seres biológicos; por supuesto, esto es lo que se ve, pero somos seres integrales, donde hay al menos las dimensiones psicológicas, sociales, ecológicas, espirituales. Todos estamos caminando en esa fila del desarrollo y del envejecimiento, y esperamos llegar para la vejez. Entonces el envejecimiento tiene que ver con el curso de vida, mientras que la vejez es un momento vital que, como parámetro cronológico según las Naciones Unidas, es de 60 años para países en desarrollo y 65 para desarrollados. (Anónimo 3, conversación personal, 2015)

El eje de envejecimiento activo fue un aporte que hizo la Organización Mundial de la Salud (OMS) a la Segunda Asamblea Mundial sobre el Envejecimiento (8-12 de abril 2002, 
Madrid, España), que habla de envejecimiento activo. Este es la optimización de oportunidades en salud, participación y seguridad a medida que envejecemos. Es para todos, y la gente lo ha tomado por el lado de envejecimiento activo, entonces como dice activo creen que es ejercicio físico (claro que lo incluye pero no es lo único), porque mirado desde la definición es la optimización de oportunidades y es para todos, no solo para los mayores, pero la gente toma rápido las dos palabritas envejecimiento activo y lo transforma a vejez activa y punto. (Anónimo 3, conversación personal, 2015)

La actualización de la política se realizó con la intención de avanzar en la precisión de algunas acciones, en especial en salud, así como en la validación y adopción de la política a nivel territorial con distintos actores como "la academia, las secretarias de salud, de desarrollo social, de familia, de participación social, ONG y centros de protección social”:

Actualmente, hay una resolución que reglamenta la Ley 1091/2006, de 8 de septiembre, que es sobre los derechos y beneficios de las personas mayores. Es la que establece el ciudadano de oro, con una resolución en la cual se espera que mejore la calidad de la atención en salud para las personas mayores. Particularmente en las citas médicas. Se prohíbe las agendas para las EPS, que las personas llaman y dicen no, no hay agenda y llame hasta el próximo mes, eso se eliminó. Con la resolución y la reglamentación, tienen ocho horas en el día para pedir la cita. Antes era solo de 7 a 8 de la mañana. Para las personas mayores, ya no pueden hacer eso, tienen que mejorar la calidad de servicio y también una diferenciación en la calidad de la persona mayor. El trato no es igual para todo el mundo, porque la persona mayor tiene más complejidades en sus patologías, y es más demorada para expresar lo que siente. Un joven llega y dice me duele la cabeza, y me duele aquí. La persona mayor no, porque, precisamente por las complejidades que tiene, se demora mucho más en las citas. Entonces digamos que la resolución mejora la calidad de los servicios; también se expidieron dos circulares en las que se establece el mejoramiento de las condiciones de salud de la atención médica a las personas mayores.

Con el ajuste de la política, se quiere cambiar las líneas de acción, sobre todo las líneas de acción en cuanto a las obligaciones que tienen las entidades y las instituciones. En el marco de las competencias, queda establecido cómo debe cada entidad territorial y cada institución responder a las necesidades de envejecimiento y vejez. En la medida en que la política no solo es para vejez, para personas adultas mayores, sino para todo el proceso de la vida, contemplando que empezamos a envejecer desde niños. [...] Por decir algo, en el enfoque de género, el primer texto de la política salió muy como con responsabilidades del Ministerio de Salud y la Protección Social, pero no eran claras las responsabilidades de cada departamento, los distritos, de las mismas personas mayores, las autoridades [...] Entonces, la actualización de la política tiene algunos aspectos más precisos, que se están 
validando. Se hicieron cinco talleres regionales que se realizaron en Bogotá, Medellín, Cali, Bucaramanga y Santa Marta. Eran regionales porque participaban varios departamentos en cada uno de esos talleres. Ahí se hizo un ajuste a las metas, que quedaron en el Plan Decenal de Salud Pública, porque la Política Nacional de Salud describe el Plan Nacional de Salud, y las políticas sociales dirigidas a las poblaciones que se enmarcan en el Plan Decenal de Salud Pública. (Anónimo 1, comunicación personal, 2015)

\section{La familia y el hogar en la política}

En relación con la familia y el hogar, ambos documentos se orientan por el mandato constitucional y el enfoque de derechos humanos. Una vez más se declara que el bienestar de las personas de edad es responsabilidad de la acción simultánea del Estado, la sociedad y las familias. Se entiende que el envejecimiento humano es un proceso social que está condicionado por el curso de vida de las personas, es decir que los sucesos históricos, las transformaciones demográficas, económicas, sociales y culturales van moldeando las trayectorias individuales, familiares y generacionales, por lo que se espera que, a partir del envejecimiento activo de la población, así como de las acciones de los sistemas de protección integral y de empleo, las personas de edad puedan conservar sus dinámicas de participación y productividad, y continúen siendo parte activa reconocida en sus entornos familiares y comunitarios, además de poder elegir libremente la forma residencial en la que prefieren vivir.

Parte de los objetivos generales de esta política es influir en las condiciones sociales, económicas, políticas y culturales de los individuos y las familias como medio para que las personas de edad de hoy y el futuro tengan una vida autónoma, digna e integrada, desde un enfoque de derechos humanos. En ese contexto, la familia se reconoce como una unidad funcional de la sociedad, compuesta por sujetos de derecho que tienen deberes con ellos mismos y sus miembros, para el adecuado funcionamiento del sistema familiar.

A la familia como unidad básica de la sociedad, que desempeña una función fundamental en la organización y el desarrollo social y que como tal debe ser fortalecida, prestándose atención a los derechos, las capacidades y desventajas y las obligaciones de sus integrantes, en torno al cuidado y autocuidado de sus miembros, en especial de las personas adultas mayores (MinSalud, 2014).

Dentro de los valores y principios que orientan esta política, se encuentran tres relacionados con la conceptualización de la familia: 1) autonomía, 2) solidaridad y 3) igualdad. La autonomía se relaciona con el autocuidado de las personas, la solidaridad con el cuidado de los otros y la igualdad con la condición de sujeto de derecho que tiene cada uno de los integrantes de la familia.

Autonomía, toma de decisiones de las personas adultas mayores en todos los asuntos que les competen, desde los más privados hasta los públicos. Representa la capacidad 
de tomar decisiones mediando una argumentación personal, y la posibilidad de llevar a cabo la decisión tomada; es decir, de materialización la decisión tomada, asumiendo las responsabilidades y consecuencias derivadas. La capacidad para decidir se da cuando no solo hay ausencia de coacción externa, sino cuando se dispone de los recursos que se precisan, en forma de bienes y servicios, y además se está en circunstancias personales y sociales que permiten aprovecharlos.

Solidaridad, asociación y organización de individuos para satisfacer necesidades e intereses comunes, con base en la cooperación, el apoyo mutuo y la dependencia recíproca entre seres humanos. La solidaridad intergeneracional hace referencia al apoyo que se da entre generaciones con el propósito de protegerse mutuamente y facilitar el buen trato, el respeto recíproco y una imagen adecuada de la vejez.

Igualdad, la Política Nacional, desde la especificidad que le es propia, reconoce y promueve el principio de acuerdo con el cual todos los seres humanos nacen libres e iguales en dignidad y derechos y, dotados como están de razón y conciencia, deben comportarse fraternalmente los unos con los otros (ONU, 1948), y deben recibir la misma protección y trato de las autoridades y gozar de los derechos, libertades y oportunidades sin ningún tipo de discriminación. (MinSalud, 2014)

La actual perspectiva del sistema de protección social se fundamenta en los derechos que, a través de acciones (estrategias, políticas, planes, programas y proyectos) encaminadas a las personas, familias y comunidades, espera reducir las desigualdades sociales, en particular frente a la discriminación laboral, y garantizar las condiciones para el bienestar de las personas de edad (MinSalud, 2014).

A pesar del amplio reconocimiento que los instrumentos internacionales, regionales y nacionales hacen de la familia y el hogar en el bienestar de las personas de edad, los avances de la implementación de la política nacional de envejecimiento y vejez tienen grandes desafíos respecto de la formación y consolidación de redes de apoyo formal e informal, servicios de atención domiciliaria, programas de uso del tiempo libre, programas de voluntariado, programas de apoyo en infraestructura y transporte, entre otros. $\mathrm{Al}$ igual que frente al cambio de la influencia que siguen teniendo las bases conceptuales del surgimiento de la institucionalización del envejecimiento, en las que la vejez se entendía como un estado de carencia que se solucionaba con actos de caridad o solidaridad informal. Esta representación de la vejez como déficit es uno de los principales obstáculos para el avance efectivo de las políticas públicas hacia la garantía de la salud y el bienestar como derecho en una sociedad para todas las edades. Hay una tensión entre las bases conceptuales y acciones de origen con las declaraciones políticas y avances normativos que orientan actualmente la institucionalización del envejecimiento del país. 


\section{Avances y tensiones de la Política Nacional de Envejecimiento y Vejez}

La reproducción de un enfoque asistencialista, junto con la escasa articulación y coordinación entre las políticas e instituciones, las limitaciones presupuestales, los desiguales avances territoriales, la ausencia de definiciones y los límites en la concurrencia del Estado, la sociedad civil y la familia para la protección social de las personas de edad, la ausencia de definiciones y acciones para el fomento de solidaridades formales e informales y la escasa oferta de servicios sociales de prevención son parte de los aspectos que retrasan el avance del proceso de institucionalización del envejecimiento en el país. Sin embargo, son varios los esfuerzos y avances con los que cuenta el país, aunque la fuerza del asistencialismo y la mirada deficitaria de la vejez son los principales orientadores del proceso de institucionalización del envejecimiento humano y vejez en el país. Es necesario reconocer los avances y esfuerzos que se están haciendo para cambiar la dirección del proceso hacia las actuales declaraciones políticas internacionales, regionales y nacionales.

Hasta el momento, los servicios que concretan las acciones de dicha política en la vida cotidiana de los colombianos son los Centros Día y los Centro de Protección, así como los subsidios económicos de alimentación y aporte en pensión. Ambos dirigidos a la población vulnerable, no a toda porque depende de los cupos que tengan disponibles los programas. Esto varía en cada territorio del país, según los recursos, el posicionamientodel tema en las agendas políticas y su inclusión en los planes de desarrollo y ordenamiento territorial. Los mayores avances de la implementación de esta política se observan en Bogotá. ${ }^{13}$ Los servicios se prestan a partir del Proyecto 742:

Su objetivo es contribuir a la reducción de la discriminación por edad y la segregación socioeconómica de las personas mayores en la ciudad, mediante la implementación de estrategias de gestión transectorial, atención integral, desarrollo de capacidades y potencialidades, transformación de imaginarios y prácticas adversas sobre el envejecimiento, así como la ampliación y fortalecimiento de la participación con incidencia de esta población. (Informe medición de satisfacción de la ciudadanía Proyecto 742 “Atención Integral a Personas Mayores: disminuyendo la segregación y discriminación socioeconómica” Desarrollo de Capacidades y Potencialidades en Centros Día)

Según las entrevistas realizadas a algunos de los coordinadores -líderes- del proyecto en distintas localidades de Bogotá, donde se encuentra uno de los mayores avances del proceso de implementación de esta política a nivel nacional, que se desarrolla en continuidad con los servicios que se vienen prestando desde las administraciones anteriores. En este sentido, la política registra la continuidad de los subsidios, Centros Día, Centros Noche ${ }^{14}$ y Centros de Protección, que han sido la forma de atender históricamente a esta población (Jaramillo y Forero, 2015). 
Estos servicios llevan un proceso administrativo de ingreso similar en todas las localidades de Bogotá. Actualmente, los ofrecidos y encargados de operacionalizar la Política Pública Social para el Envejecimiento y la Vejez (PPSEV) son el Servicio de Apoyo Económico, Centros Día, Cetros Noche y Centros de Protección. Todos los servicios se encuentran vinculados por un enfoque de desarrollo humano que busca ir más allá de la asistencia que brindan los servicios y contribuir en el desarrollo y fortalecimiento de las capacidades y potencialidades relacionadas con la participación, la incidencia, el cuidado, las redes sociales y familiares de la personas mayores (Informe medición de satisfacción de la ciudadanía Proyecto 742 “Atención Integral a Personas Mayores: disminuyendo la segregación y discriminación socioeconómica” Desarrollo de Capacidades y Potencialidades en Centros Día).

El Servicio de Apoyo Económico es el que tiene una mayor trayectoria y reconocimiento social; aunque la población objetivo son todas las personas en condiciones de vulnerabilidad, existen unos criterios de priorización, ${ }^{15}$ como que vivan en la localidad y tengan condiciones de vida precarias. Si cumplen con estos requisitos, ingresan a una lista de espera según los cupos disponibles en el proyecto. En el caso de que la persona reciba el subsidio, se realiza un seguimiento periódico para revisar su supervivencia y, si sus condiciones de vida han mejorado, se retira el subsidio. Esto también se aplica para las áreas rurales, sin embargo, las distancias y la escasez de recursos para transportarse son obstáculos adicionales para esta población.

La generación de recursos para el subsidio económico no es una responsabilidad exclusiva de la Secretaría Distrital de Integración Social, sino que también depende de las alcaldías locales y de la Presidencia. Para Bogotá, hay tres tipos de subsidios: dos provienen de fondos del Distrito y las localidades y uno de la nación (Jaramillo y Forero, 2015).

El subsidio D, que es un subsidio que es de la Nación. Eso lo maneja Prosperidad Social de Presidencia de la República, desde el programa “Colombia Mayor". ${ }^{16}$ Se encuentra en toda la nación, es entrega de dinero en efectivo por un monto de \$150,000 pesos, cada dos meses en todo el territorio nacional y tiene unas características, que hace que a ese subsidio, entren las personas más vulnerables. Para acceder, la persona tiene que tener Sisben inferior a 39 puntos. Esto quiere decir que si la persona no tiene el último Sisben, no podemos hacer nada para priorizar. Tener un Sisben de 39 puntos, significa que no tienen electrodomésticos, que comparten cocina, comparten baño, la situación habitacional no es buena. Si son las personas más vulnerables, se les está dando menos plata. Porque eran $\$ 150,000$ pesos cada dos meses. Entonces lo que el Distrito hizo fue colocar una inyección de dinero, para que quedara igualado a los otros dos subsidios. Entonces a ellos se les dan \$240,00o pesos cada dos meses. Sin embargo, esos subsidios no son vitalicios, eso depende de las condiciones de la persona. Por eso es tan importante el seguimiento. 
Nosotros entregamos subsidios y no soltamos a la persona ahí. Estamos permanentemente mirando cuál es la situación de ese adulto mayor, y si sigue ameritando la entrega de esos recursos. (Jaramillo y Forero, 2015, p. 304)

El único programa nacional es Colombia Mayor, desafortunadamente el subsidio es muy pequeñito, empezó en 150 ooo, y ya va en 75 ooo. Se supone que esos recursos solo van para personas que tengan más edad y no tengan redes de apoyo, propiedades o ingresos.

(Anónimo 2, conversación personal, 2015)

El tipo de subsidio y su monto depende de los recursos adicionales que inviertan las autoridades departamentales, municipales y locales. Es una combinación entre los lineamientos de la nación, los municipios y las autoridades locales, aunque tanto el monto básico que aporta la nación como el mecanismo de entrega es igual en toda las localidades del país (Colombia Mayor Consorcio 2013).

La principal estrategia que se ha implementado en Bogotá para superar la tendencia asistencialista de los servicios sociales que operacionalizan esta política es la inclusión del enfoque de desarrollo humano en los servicios. Esto se hace a partir de talleres de capacitación, que tienen como propósito ofrecer nueva información a las personas de edad para que progresivamente vayan haciendo uso de las rutas de acción que tienen para ejercer sus derechos y convertirse en ciudadanos activos con autonomía política y social (Jaramillo y Forero, 2015).

A nivel nacional, también se están haciendo esfuerzos por superar la lógica asistencialista y orientar la implementación de la política hacia el enfoque de derechos y desarrollo humano. En este sentido, se está avanzando en los diálogos entre distintas políticas que involucran a la población de edad, pero que actúan de forma fragmentada, lo que dispersa los recursos y reduce la influencia que estas en conjunto pueden tener en la mejora de las condiciones de vida de las personas de edad y sus familias. Las políticas que, inicialmente, se están revisando para articular con la de envejecimiento son familias, discapacidad y habitanza de calle.

El ejercicio que se intentó hacer con la actualización de la política fue mirar otras políticas, como la de familias, porque ya no es un solo tipo de familia, sino que son diversas familias. También la de discapacidad y la de habitanza en calle. Se están mirando todas las políticas que hay en este momento a nivel nacional, para que unas con otras se conversen. Con la política de familias, se ha tenido una mayor receptividad, porque se comprende que el envejecimiento y la vejez es un proceso, que se puede trabajar con los grupos familiares. Entonces el tema de familias ayuda como una red de apoyo fuerte. La dificultad es que las políticas no se conversan. En las políticas de niñez, de juventud, de adultez a nivel 
nacional, no hay nada de envejecimiento y vejez. Entonces queda un vacío. La idea es que estas políticas también se contemplen como curso de vida, no solo como una etapa puntual, de la que sale la persona, y queda sin acciones, sin rutas de acceso para el ejercicio de sus derechos. La idea es que esas políticas también tengan una corresponsabilidad, una unión entre ellas. (Anónimo 2, Comunicación personal, 2015)

Falta la articulación, por ejemplo, con la política Cero a Siempre. La política de envejecimiento humano, como se va a llamar ahora, y vejez, debería estar muy articulada con eso de Cero a Siempre, con familias, con género, con desastres, con todo, porque es que nos incluye a los seres humanos, y ¿dónde no está el ser humano? (Anónimo 3, conversación personal, 2015)

Una forma de avanzar en la socialización e implementación de la política han sido los Encuentros Nación Territorio, que son sesiones que se realizan en el Ministerio [de Salud y la Protección Social], desde 2013, de forma virtual, una vez al mes. Se elabora una programación anual de temáticas generales. La familia es uno de los temas que se han presentado en estos encuentros, en un intento por acercar las políticas de envejecimiento y vejez con la de familias.

Se trabaja con envejecimiento y vejez y familias, se quería incluir otras temáticas, pero la política de discapacidad tiene otro ritmo y habitanza en calle también [...] Es importante tratar de hacer un solo encuentro de todas las políticas, no tantos encuentros virtuales, porque en las entidades territoriales, por lo general, los referentes de las distintas políticas son las mismas personas que en el departamento se encargan de adultos mayores, discapacidad, el SIGER, SISPRO, salud pública, ellos atienden muchísimas cosas. Entonces en las entidades territoriales los profesionales están cargados con las temáticas [...], se trata, por lo menos en este año, de hacerlo con familias. Vienen personas de todo, Bogotá, Chía, varios municipios de Cundinamarca que pertenecen a los consejos, como es el caso del distrito o consejos de localidades, instituciones que brindan apoyo a personas mayores, instituciones que trabajan con personas mayores, hemos tenido muy buena participación del SENA, sus estudiantes están trabajando aspectos de salud o cuidados [...] Como no todas las personas pueden acercarse a Bogotá, lo que permite la plataforma es el acceso por medio de un link y se conectan. Las sesiones quedan grabadas, entonces las pueden consultar en la página. Están publicadas las presentaciones y memorias de 2013 y 2014, también las de este año. Siempre se hacen en el mismo horario, para que a las personas no se les olvide, eso como que ha calado y ayuda, en el último encuentro llegaron alrededor de 140 personas. (Anónimo 2, conversación personal, 2015)

La territorialización de la política nacional es una de las prioridades para el avance de su implementación. A partir de ella, es que se pueden establecer proyectos y programas, 
adecuados a las particularidades locales, que permitan desarrollar las líneas de acción de la política. El Ministerio de Salud y Protección Social es el encargado de brindar asistencia técnica a los departamentos y orientar las líneas de acción, ya que son rectores de la política. Para esto brindan capacitaciones a las entidades territoriales, en especial a las secretarías de salud, por ser los pares directos en los departamentos. Los recursos no se pueden asignar a otras instituciones, aunque trabajen el tema de envejecimiento y vejez. Estos se asignan con unos lineamientos específicos, orientados hacia el cambio de las mentalidades respecto al envejecimiento y la vejez. Cada vez más, se intenta que ese cambio de mentalidad se relacione con proyectos y programas que brinden herramientas a las personas mayores para contribuir a su independencia y autonomía, y menos con actividades de corto plazo o asistencialistas. Sin embargo, los limitados recursos que tienen los municipios se convierten en un obstáculo para poner las contrapartidas necesarias, tanto económicas como en equipo de trabajo, para desarrollar iniciativas de amplio alcance. Además, la no inclusión del envejecimiento y la vejez en los planes de desarrollo y ordenamiento territorial limita las oportunidades de inversión y avance. La implementación de la política depende en gran medida de las prioridades que tengan los municipios y de su comprensión acerca del proceso de envejecimiento demográfico y su impacto en el desarrollo territorial. (Anónimo 1, conversación personal, 2015)

La idea es cambiar, un poco, la mentalidad de las personas. Que no sean dependientes, sino que en realidad les den herramientas que sí les vayan a servir para toda su vida independiente. Los lineamientos de la política tienen unas líneas de acción específicas. La idea es que las entidades territoriales puedan colocar las contrapartidas, que casi siempre son muy limitadas. Casi no tienen recursos para desarrollar estos temas. (Anónimo 2, conversación personal, 2015)

La dificultad es que las entidades territoriales, o las mismas personas mayores, o las instituciones, no han tenido la tarea de revisar el documento de la actualización de la política, el ejercicio de mirar si eso aplica o no. Porque por decir, en las ciudades capitales de los departamentos, es fácil aplicarla, pero hay unas coyunturas particulares en las partes municipales, en la parte rural, y con todo el tema ahora del proceso de paz. Hay que trabajar con diferentes tipos de población, que cambia según los territorios. Esos son ejercicios necesarios, ahora vienen los planes de desarrollo, y si las temáticas no quedan incorporadas en ellos, la política no va a tener fuerza vinculante para su realización. De todas formas, uno de los ejercicios más importantes es que las personas, la sociedad en general, las instituciones que trabajan con personas mayores, conozcan los documentos y hagan observaciones. (Anónimo 2. Conversación personal, 2015) 
Se necesita que los departamentos tengan un diagnóstico. Saber cuántas personas mayores hay, cuántos son hombres, mujeres, cuántos en la zona rural y en las cabeceras municipales. Identificar la problemática, ellos mismos, cuáles son sus necesidades. Ahí salen muchas temáticas, y cuando se les pide volver eso en positivo, y buscar las soluciones, ahí hay un cuello de botella. Porque identifican el problema, pero no saben cómo solucionarlo. No saben dónde ir a plantear la queja y dónde buscar la solución. El reto es responder a esas necesidades. Hace tres años se presentó un caso. Vinieron de un municipio, muy preocupados, porque tenían varios casos de personas adultas mayores que se estaban muriendo por hambre. Entonces el alcalde en su momento, buscando, no una solución asistencial, propuso un proyecto, muy bien elaborado, en el que consiguió lotes baldíos, tierra y semillas, y con otras entidades, empezaron a sembrar. El trabajo más pesado lo hacían personas adultas, se pagaba, tenían cuantificado en el proyecto lo que se iba a pagar. El trabajo más liviano lo hacían, inclusive, las personas mayores. Utilizaban productos orgánicos, los productos que no se consumieran ahí, y los vendían en las instituciones que trabajan con personas mayores. Entonces había como una corresponsabilidad. Creo que esos programas tienen que ser a largo plazo. Otro ejemplo interesante es una empresa del sector privado, tiene algunos proyectos productivos. En algún momento tuvimos el acercamiento con dos departamentos, que tienen un trabajo con personas mayores que trabajan el tejido de los sombreros. Los que tejen son personas mayores y la empresa los asesora. (Anónimo 2, conversación personal, 2015)

Los procesos de territorialización e implementación de la Política Nacional de Envejecimiento Humano y Vejez enfrentan distintos obstáculos asociados, por una parte, a las condiciones sociales y económicas desiguales del país, que se reflejan en una alta participación laboral en el mercado informal; y por otra, al escaso desarrollo institucional que se expresa en la baja cobertura de seguridad social, que no supera a una cuarta parte de la población de edad. En este contexto, se aumentan los riesgos de que los efectos negativos del envejecimiento se agudicen, no solo para las personas mayores, sino para sus familias, en especial para las mujeres. Los asuntos que se muestran como prioritarios para superar los obstáculos mencionados se relacionan en especial con tres aspectos: 1) autonomía, 2) solidaridad formal e informal y 3) igualdad.

El primero se asocia con la capacidad de tomar decisiones independientes de los deseos de los demás, tanto en la vida privada como en la pública. Decisiones fundamentadas en los motivos y razones personales, así como en las condiciones para realizar y materializarlas, asumiendo sus responsabilidades y consecuencias. Esta capacidad para decidir se puede desarrollar cuando hay ausencia de coacción externa, se dispone de los recursos materiales y no materiales necesarios y se tiene un respaldo normativo y social que facilite el desarrollo de la decisión. Este respaldo social está relacionado con las representaciones sociales de la vejez. Actualmente, la vejez es sinónimo de carencia, 
deterioro e inutilidad. Todos con un sentido de discriminación, que ubica a la población anciana en una condición de desigualdad y dependencia, que distorsiona la realidad y diversidad de la vejez contemporánea. Además, la equivalencia que se hace entre envejecimiento y vejez contribuye al significado de creer que las otras edades se encuentran a salvo de tal situación deficitaria.

Yo he estado trabajando los últimos años en los estereotipos, porque me preocupa que esos imaginarios sesgan completamente. Si tienes el imaginario de pobrecito, deterioro, qué horror, inservibles, tú vas a trabajar así. Mira que ya tenemos un nuevo síndrome, y yo les dictaba clase a los de una maestría, y les decía que un nuevo síndrome que estamos atendiendo es el de Dorian Grey. Ya tenemos muchas personas mayores que se niegan, y hacen mil maromas... entonces uno ya vuelto miseria, porque además no ha hecho nada en la vida para cuidarse, en eso también estamos trabajando, en lo de que los años no vienen solos... Mientras no trabajemos, no compartamos estereotipos y no hagamos capacitación, yo creo que esto no funciona, puede quedar en el papel muy lindo, pero necesitamos tocar piel, y decirle a la gente, usted es corresponsable con su desarrollo, y con su envejecimiento, y debe modificar esas miradas. Nosotros queremos y tenemos una visión diferente de los viejos que conocemos o son familiares pero de los otros no... "No, mi abuelo sí es chévere, mi abuelo sí es inteligente, mi abuelo no está deteriorado pero los otros quién sabe”. (Anónimo 3, conversación personal, 2015)

Estos prejuicios respecto de la edad constituyen el primer y principal obstáculo en cuanto a la creación de condiciones de posibilidad para que tanto las personas de edad como las de otras edades transformen los significados y sentidos tradicionalmente asociados a la vejez. En este sentido, la formación de la autonomía no se puede limitar a la población de edad, porque tiene que ver con un aprendizaje que se hace a lo largo de la vida, y que no es individual, sino colectivo, incluye todas las interrelaciones que se tienen con los distintos grupos sociales (familia, amigos, vecinos, etc.). Esto se encuentra vinculado al enfoque de curso de vida y envejecimiento activo, en el que el bienestar de la vejez está condicionado por los aprendizajes que se han hecho a lo largo de la vida, así como por las oportunidades que la sociedad ha ofrecido en relación con la educación, el trabajo y las redes de apoyo, las cuales se acumulan en la trayectoria personal y condicionan la experiencia continua de envejecimiento y la vivencia de la vejez.

Bueno, yo creo que básicamente para poder desarrollar el tema de envejecimiento activo es necesario considerar las disposiciones particulares del ser humano para que se pueda desarrollar como lo considere individualmente. En las ciudades, se contempla como desarrollo hacer ciertas actividades intelectuales, físicas, laborales, profesionales; pero, en 
otras lugares, de pronto lo que importa es transmitir y apoyarse comunitariamente, por ejemplo, con los temas de las etnias y comunidades afro. No a todos nos llama la atención lo mismo. Depende del entorno donde se desarrolle ese ser humano, entonces, ahí sí depende de todas las posibilidades. Eso va muy ligado como a un equilibrio, no solo lo que percibamos, no solo las acciones físicas, intelectuales, sino también una alimentación equilibrada, de ciertos hábitos saludables que van a potencializar y favorecer cierto bienestar del ser humano. (Anónimo 2, conversación personal, 2015)

La toma de decisiones con independencia requiere que el sujeto desarrolle un conocimiento sobre su propio proceso de envejecimiento físico y mental como ser humano, el cual se construye a partir de la información y las experiencias que cada persona va teniendo en su trayectoria de vida, y que orientan su comportamiento. Estas experiencias se encuentran interrelacionadas con las condiciones sociales en las que se desenvuelve el sujeto. Dependiendo de esas relaciones entre el sujeto y su ambiente, se pueden desarrollar comportamientos conscientes del propio organismo, y de su relación con los estados de bienestar o malestar. El conocimiento acerca de la influencia que tienen los hábitos de alimentación, sueño, ejercicio y relaciones sociales satisfactorias en la calidad de vida de las personas puede crear condiciones de autorregulación que favorezcan el proceso de envejecimiento. Estos aspectos han sido estudiados y se consideran centrales para el bienestar de las personas a lo largo de la vida, pero en especial en la vejez (Buettner, 2016). Estas decisiones no son hábitos voluntarios individuales, sino que dependen en gran parte del ambiente social en el que se desenvuelva la vida de la persona. La oferta de condiciones saludables para las personas es un asunto que le corresponde a la sociedad en su conjunto, en especial al mercado y las instituciones, ya que son los principales productores de bienes y servicios de consumo. La familia, las comunidades y los sistemas educativos tienen una gran influencia en la formación de la conciencia sobre el propio funcionamiento biológico y social del cuerpo. Estos entornos pueden ofrecer las condiciones para que los sujetos desarrollen distintas capacidades que les den la posibilidad de construir una valoración de ellos mismos y de los otros. La construcción de una valoración respecto de sí mismo tiene que ver con el reconocimiento, la expresión y la valoración de las emociones, así como con la capacidad de razonar y establecer una distancia que facilite la acción de escuchar y realizar acuerdos. La autonomía requiere que los sujetos puedan sentir, analizar y evaluar sus circunstancias, con el fin de elaborar criterios y argumentos que orienten su acción frente a las distintas circunstancias de su vida y resolver sus problemas. Las emociones y el razonamiento son un continuo en el sujeto, que, dependiendo de las condiciones en las que se construye, varía su influencia en el comportamiento. Un sujeto autónomo en su vejez es un sujeto que lo ha aprendido a lo largo de su vida, porque las condiciones de 
su existencia lo han permitido, ha aprendido a tomar decisiones ajenas a los deseos de los demás, orientadas por ambientes sociales que favorecen su autodeterminación. En la medida en que este aprendizaje no se produzca en los momentos tempranos de la vida, se hace más difícil que la persona pueda ser autónoma, tomando decisiones y resolviendo sus problemas. Y si su entorno social y normativo no ha desarrollado condiciones para la realización de la autonomía, es todavía más difícil pretender que los ancianos sean autónomos. En este momento, el país no cuenta con las condiciones para la autonomía en la vejez. La implementación de la política está comenzando, los marcos normativos no son suficientes para garantizar los derechos económicos, como es el caso de la pensión, los servicios que se ofrecen en este momento son asistenciales, la formación educativa de la gran mayoría de las personas mayores es baja y las representaciones sociales de la vejez se relacionan con los significados de dependencia y carencia.

Parte de las condiciones necesarias para el ejercicio de la autonomía en la vejez son la solidaridad formal e informal. La primera se refiere a las acciones del Gobierno y del sector privado y la segunda a las que provienen de la familia, los amigos, los vecinos, la comunidad en general. Esta última es la que se ha dado de forma tradicional, en especial en las familias, que se funda en los lazos de consanguinidad. Es la que históricamente ha sostenido las redes familiares y, en ellas, a las personas de edad. Sin embargo, los cambios sociales del siglo XX transformaron las condiciones en las que se daba este tipo de solidaridad, en especial en el paso del campo a la ciudad, en la división de lo doméstico y lo productivo y en la significativa reducción del tamaño de las familias. De esta forma, el rol de las instituciones públicas y privadas ha sido cada vez más importante para que las familias, pero en especial los niños y viejos, puedan tener una protección social e integral. Las generaciones viejas hoy no tuvieron históricamente acceso a la protección social institucional pública, que empezó en la segunda mitad del siglo XX. Además, las condiciones de formalización del trabajo para estas generaciones fueron muy limitadas, lo que se refleja en la baja cotización que hicieron al sistema pensional.

En este sentido, los viejos de hoy viven una situación que es producto de transformaciones generales de la sociedad, y que es injusta, en la medida en que no les permite acceder a una seguridad social y económica que no acumularon porque las condiciones no lo permitían, más allá de su voluntad de ahorro y previsión. La familia y las generaciones de adultos y jóvenes están compensando la inseguridad económica y social de las condiciones históricas en las que se desenvolvieron las generaciones que hoy son viejas. Existe una sobrecarga para las familias de las personas de edad, y para ellos mismos que siguen trabajando a fin de sostener o aportar al hogar. Esta presión no encuentra una solidaridad formal o estructurada por parte de las instituciones públicas y privadas. Los instrumentos internacionales, regionales y nacionales mencionan en repetidas veces la importancia de que las personas de edad cuenten con solidaridades 
formales e informales, pero no se precisa el contenido de cada una, ni se establecen límites o responsabilidades particulares que se relacionen entre ellas para actuar en concordancia con el mandato institucional y con la política, en las que se declara que existe una corresponsabilidad por parte del Estado, la sociedad civil y la familia. De igual forma, tampoco se encuentra en los deberes del Estado y la sociedad civil la obligación que tienen de ser solidarios con la familia, pero sí se les exige a la familia y a la persona mayor cumplir con una serie de deberes que garanticen la calidad de vida individual y colectiva. Esto termina por reproducir el escenario tradicional de la protección social, pero aumentando los efectos negativos del envejecimiento, en la medida en que las familias tienen menos personas y deben responder a demandas laborales y personales, que reducen significativamente la posibilidad de quedarse en el hogar cuidando a los otros integrantes. Además, quienes se quedan en el hogar cuidando a niños y ancianos luego son castigados por la sociedad porque no generaron unas condiciones de ingreso económico que les permitiera cotizar para la pensión. Esto se aplica para las generaciones hoy viejas, pero para las generaciones en edades productivas que se encuentran envejeciendo el problema es más complejo, puesto que la oferta de educación y trabajo sigue teniendo dificultades para garantizar al total de la población su derecho a la educación y el trabajo. Además, las representaciones sociales en torno a la cotización para salud y pensión se asocian a una desconfianza con las instituciones del Estado y el sector privado y al sentimiento de negación del envejecimiento, los riesgos de salud y la vejez.

Sin embargo, para el tema de seguridad social e integral, la informalidad es una de las cosas que mata al país, porque son muy pocos realmente los que sustentan la población de dependencia, que son los menores de 15 años que deben estar estudiando, y los mayores de 60 porque ya no están en la parte productiva, pueden estar generando ingresos pero ya no tienen que sostener a otros, aunque eso es relativo, porque aquí muchas de las personas mayores que tienen pensiones sostienen a los hijos desempleados o se dedican al cuidado de los nietos. (Anónimo 1, conversación personal, 2015)

Esto sí es histórico, es que la informalidad en Colombia afecta el tema de las pensiones. Por eso es que en este momento hay un gran esfuerzo por aumentar la cobertura de pensiones para las personas que trabajan en transporte, salones de belleza, los que tienen arrendamientos y no aportan al sistema... es que la gente piensa que nunca llega a ser viejo. Porque la gente dice: “Ay, no, yo empiezo a aportar cuando tenga 40 años”. Cuando tenga 40, ya va a ser demasiado tarde porque usted nunca sabe... se montó en una bicicleta y quedó con un traumatismo craneoencefálico y quedo cuadripléjico. ¿Quién lo va a mantener? Y si en su casa nadie aportaba, entonces es muy difícil, es que uno tiene que pensar que la vida no es que usted se muera a los 80 años, hay un 
promedio, una esperanza de vida, pero usted puede tener situaciones de dependencia antes. ¿̇O cuándo se muere uno? Hay gente que muere al año de nacido, porque la muerte es el cualquier momento, entonces estar en el Sistema de Seguridad Social desde un principio es fundamental. Es como otra gente que dice: "No, yo soy independiente, por consiguiente, yo no aporto sino solo el mínimo”. Pero cuando llegan ya a la edad y quieren aportar ya no pueden, solo un poco más para que la pensión le salga mejor. Ya no puede porque ahora le sale el promedio de pensión por los diez últimos años, no el último año que se afilie. Entonces no hay conciencia, pienso que falta más presión e información por parte del Estado para que la gente mire la importancia de estar en un sistema de seguridad social. (Anónimo, 1. Conversación personal, 2015)

La solidaridad formal, actualmente, se resuelve con subsidios. Para el caso de la vejez, el programa Colombia Mayor es la forma más concreta de solidaridad formal con los ancianos. El subsidio varía entre 45000 y 75 ooo pesos cada dos meses. Sin embargo, frente a la imposibilidad de garantizar la seguridad económica de las personas de edad, mediante su derecho a una pensión, se propone una acción orientada hacia la cultura y la valoración de las inversiones en las condiciones no materiales de las personas de edad, una mirada que integre los distintos esfuerzos que se hacen desde los proyectos y programas sociales.

La del subsidio trasciende todas las acciones que se están haciendo complementarias a lo de Colombia Mayor, como el desarrollo del cultura con danzas, juegos tradicionales, instrumentos. También están los Centros Vida y los Clubes de Personas Mayores. Unos se llaman Consejos Distritales, otros se llaman Consejos de Sabios, otros se llaman Comités de Adulto Mayor, varía, y el tema de la participación está ahí y ellos definen lo que quieren hacer. Porque una persona que recibe el subsidio puede estar haciendo planes de pintura o un proyecto de generación de ingresos, como los impulsa el Ministerio de Agricultura. Entonces el tema de subsidio lo critica todo el mundo y ḋquiénes lo critican? ¿Los jóvenes o las familias que no reciben ningún subsidio? Pero para la persona mayor que solo recibe 150 ooo pesos, que jamás los ha tenido, es la bendición de Dios, porque es algo que dignifica, el recibir una plata después de viejo, después de que aportó a la sociedad, después de que trabajó el campo. ¿Qué no tengan derecho de recibir nada? Me parece que son dignos de recibir algo. Y hay un derecho fundamental, que es el derecho a ser asistido, cuando usted no tiene las capacidades. Cuando usted no tiene dentro de su vida trabajo, pero nadie le habló que era importante desde joven empezar a aportarle a un sistema de seguridad social y nunca le aportó, y cuando quiso hacerlo, cuando llegó a viejo: “¿Y cómo hago para pensionarme?”. No, usted ya no se puede pensionar porque usted nunca aportó, entonces llegar a viejo y dependiendo de si alguien me quiere regalar un peso. Es terrible... en cambio, el derecho a un ingreso mínimo, que es el subsidio. (Anónimo 1. Conversación personal, 2015) 
La realidad del país es que hay muchas desigualdades y mucha pobreza. A veces el subsidio es el que sirve para comprar lo básico de alimentación, porque esa persona mayor vive con muchos familiares, hay niños y mujeres, y las personas con las que vive esta persona adulta mayor trabajan al diario y hay una inestabilidad laboral. Tanto que a veces las familias mismas dicen: "Es que no estoy trabajando, no tengo con qué", entonces también uno ve que no es porque las familias no lo quieran hacer, sino que el tema laboral en el país es bastante complejo. Esto ya hemos visto son los roces intergeneracionales por las pocas oportunidades que hay para los jóvenes, para los adultos y, pues, oportunidades para personas adultas mayores no. Un tema de los estereotipos es que tú trabajas en ciertos cargos hasta que tengas cierta edad y, si son en ciertos medios, tú tienes que estar bien o si no tú ya pasaste, ya no puedes acceder a ciertos trabajos porque es que tú tienes más edad. Entonces, se necesitan como mayores posibilidades para generar ingresos a las personas, porque también lo que vemos es que hay mucha inestabilidad laboral, ya tú no tienes un trabajo estable en donde te paguen prestaciones, seguridad social. (Anónimo 2, comunicación personal, 2015)

La sobrecarga de la familia, que es la expresión concreta de la ausencia de la solidaridad formal, trae nuevos problemas relacionados con las desigualdades sociales y económicas entre sus integrantes. Por una parte, los asuntos del cuidado, ¿quién cuida? La reducción de la familia, junto con el cambio de roles de las mujeres y las personas mayores, han desestructurado las formas tradicionales de asistencia a las personas de edad. Sin embargo, siguen siendo las mujeres las que en su mayoría asumen las responsabilidades domésticas y de cuidado. Ambas labores las enfrentan sin tener unos programas sociales domiciliarios que compensen la participación y colaboración de otras personas en el mantenimiento del hogar y el cuidado de una persona mayor dependiente. Ambas labores son de tiempo completo, la persona que cuida, por lo general, debe dejar de hacer otras actividades como estudiar o trabajar, es decir, debe dejar de lado su propia realización. Esto hace que el cuidador se ubique en un lugar desigual en relación con las personas de su edad que pueden estudiar y trabajar para desarrollar sus capacidades y avanzar hacia su realización personal. Estas desigualdades no solo se reflejan en altos niveles de frustración y cansancio, que pueden terminar en enfermedad, sino que van disminuyendo la calidad de vida, tanto del que cuida como del que es cuidado. Por lo general, la persona dependiente tampoco se siente cómoda con esa relación, para ambas partes es un proceso difícil que requiere apoyo del Estado, mediante programas de acompañamiento psicosocial y económico, que brinde herramientas a los integrantes de la familia para que puedan afrontar de la mejor manera los procesos de envejecimiento y enfermedad. Hasta el momento, la única atención domiciliaria que se brinda es de salud, en casos de emergencia o de cuidados paliativos. 
Esto ya se encuentra en los documentos de las entidades prestadoras de salud (EPS). Sin embargo, su aplicación enfrenta los problemas de personal y recursos económicos que estas tienen. No existen servicios sociales de acompañamiento y apoyo. Tampoco programas de voluntariado que fortalezcan las redes de apoyo de la persona de edad y su familia. "La mayoría de las personas adultas mayores son mujeres, y mucho de los roles y toda la carga que no se paga pero que sí se ve, y se necesita como el tema de cuidado, lo ejercen las mujeres" (Anónimo 2, conversación personal, 2015).

No son muchos los ancianos que cuentan con facilidades para que los acompañen a pedir una cita o que tengan la capacidad de hacer largas filas o de desplazarse de un lugar a otro para poder cumplir con los absurdos requisitos y requerimientos de las EPS. No son pocos los casos en los cuales el anciano requerirá tratamientos domiciliarios, y el sistema, una vez más, no está preparado para atender ágilmente este tipo de necesidades. Estos vacíos en los servicios de salud y la falta de infraestructura para atender a los ancianos acarrean consecuencias que terminan vulnerando los derechos de otros miembros de la sociedad y modificando la dinámica natural de esta. En muchas ocasiones, la responsabilidad que debería asumir el Estado "recae en las familias, que por lo general carecen de capacitación o apoyo para proporcionar la atención necesaria. Esta situación puede requerir que otro miembro de la familia, por lo general una mujer, renuncie a trabajar" (Dangond, 2015).

Según el censo de 2005, el 99 \% de las personas mayores de 60 años conviven con su familia, lo que indica que la familia es el principal cuidador de las personas mayores. La demanda por la institucionalización de las personas mayores ha ido en aumento. La política pública debe desincentivar la institucionalización de la persona mayor, la teleasistencia y atención domiciliaria tienden a cobrar mayor relevancia como modalidades de atención que promueven la autonomía personal. (Anónimo 3, conversación personal, 2015)

Las desigualdades en la familia se reflejan en el aumento de conflictos y tensiones entre los integrantes del grupo. El número de casos reportados por violencia intrafamiliar hacia las personas mayores en Colombia se ha incrementado en los últimos años, que pasaron de 965 en 2004 a 1651 en 2015. Todos causados por familiares en primer grado de consanguinidad, el 53 \% mujeres y el 47 \% hombres (Departamento Nacional de Planeación [DNP], 2017).

Ahora, hay un tipo de violencia que no se ve únicamente que es la agresión física, sino que es también la violencia económica cuando la persona mayor le cobran la pensión, o no le dan los recursos para su sostenimiento o simplemente se le deja marginado de acceder a cualquier tipo de ayuda económica, y otro tipo de violencia es cuando definitivamente se 
le hace fuera... tiempo fuera en la toma de decisiones, no se deja participar a la persona mayor en la toma de decisiones; pero eso no se visibiliza aunque sabemos que existe y sucede en muchas de las familias. (Anónimo 4, 2015)

La autonomía, la solidaridad formal e informal y la igualdad hacen parte de los principios y valores de la Política Nacional de Envejecimiento y Vejez, que son centrales para garantizar el bienestar, tanto de las personas mayores como de los integrantes de sus hogares. Sin embargo, su ausencia en los deberes relacionados con la concurrencia y las responsabilidades del Estado y la sociedad civil, así como en las acciones y los servicios específicos no permite que se creen las condiciones reales para garantizar los derechos tanto de las personas de edad como de sus familias. A la familia se le sigue exigiendo que reproduzca su función tradicional de atención y cuidado, sin considerar los cambios en sus condiciones de posibilidad para hacerlo. Esto no facilita la creación de marcos normativos y programas sociales que tengan como objetivo la promoción de la solidaridad estructurada desde las instituciones públicas. Aunque no aparece en la política y sus programas, el derecho de la familia a ser apoyada por el Estado y la sociedad se declara en la Ley 1315/2009, de 13 de julio, la cual tiene el propósito de garantizar el desarrollo integral de la familia y establecer las disposiciones para la construcción de una política pública para la familia. Sin una solidaridad estructurada y garantizada por las instituciones públicas, la autonomía y la igualdad se quedan solo como referentes ideales de la acción.

Finalmente, a pesar de los esfuerzos y avances en la institucionalización del envejecimiento y la vejez en el país, la ausencia de definición de las responsabilidades concretas del Estado y la sociedad civil en relación con la infraestructura de solidaridad formal e informal se refleja en la carencia de programas específicos orientados hacia la formación de redes comunitarias e institucionales que favorezcan las distintas formas de organización residencial desde la autonomía y la equidad intergeneracional. Según la World Values Survey (2012), en Colombia, la mayoría de las personas consideran que la independencia, la determinación, la perseverancia y la imaginación no son cualidades que se puedan promover en los niños desde el hogar, en contraste con la fe religiosa. Esto refleja las tensiones que existen entre la reproducción de valores orientados hacia las formas solidarias y familiares tradicionales y la emergencia de condiciones que requieren valores orientados hacia la autonomía y la formación de solidaridades que trasciendan la relación biológica de parentesco, en la búsqueda de ambientes comunitarios que favorezcan tanto a los que tienen amplias redes de apoyo familiar como a los que no cuentan con ese soporte, pero que también hacen parte de la sociedad, en una perspectiva de derechos. 


\section{Referencias}

Arrubla Sánchez, D. (2015). Legislación y política pública para el cambio demográfico. En P. Rodríguez Jiménez y F. Vejarano Alvarado (eds.), Envejecer en Colombia (pp. 140-171). Bogotá: Universidad Externado de Colombia.

Asamblea General, Cuadragésimo sexto periodo de sesiones (1991). Recuperado de http://www.un.org/es/comun/docs/?symbol=A/RES/46/91

Asamblea Mundial sobre el Envejecimiento. 26 julio a 6 de agosto de 1982 Viena, Austria. Plan de Acción Internacional de Viena sobre el Envejecimiento. Recuperado de http://www.sld.cu/galerias/pdf/sitios/gericuba/plan_de_accion_internacional_de_viena_sobre_el_envejecimiento.pdf

Buettner, D (2016). El secreto de las zonas azules. México: Grijalbo.

Colombia Mayor Consorcio 2013. Pago del subsidio de Colombia: mayor del mes de julio. Recuperado de https://colombiamayor.co/index.html

Comisión Económica para América Latina y el Caribe (2002). Reunión de expertos en redes sociales de apoyo a las personas adultas mayores: rol del Estado, la familia y la comunidad. Recuperado de https://www.cepal.org/es/eventos/reunionexpertos-redes-sociales-apoyo-personas-adultas-mayores-rol-estado-la-familia-la

Comisión Económica para América Latina y el Caribe (2008). Primera Reunión de seguimiento de la Declaración de Brasilia. Recuperado de https://www.cepal. org/es/eventos/reunion-seguimiento-la-declaracion-brasilia-o

Comisión Económica para América Latina y el Caribe (2009). Segunda Reunión de seguimiento de la Declaración de Brasilia. Recuperado de https://www.cepal. org/es/eventos/segunda-reunion-seguimiento-la-declaracion-brasilia

Comisión Económica para América Latina y el Caribe (2011). Presentaciones del Encuentro Internacional para el Seguimiento de la Declaración de Brasilia y la Promoción de los Derechos de las personas mayores. Recuperado de https:// www.cepal.org/cgi-bin/getProd.asp?xml=/celade/noticias/paginas/5/45035/ P45035.xml\&xsl=/celade/tpl/p18f.xsl\&base=/celade/tpl/top-bottom_env.xslt

Comisión Económica para América Latina y el Caribe (2012a). Informes nacionales. Recuperado de https://www.cepal.org/cgi-bin/getprod.asp?xml=/celade/noticias/paginas/9/46849/P46849.xml\&xsl=/celade/tpl/p18f-st.xsl\&base=/celade/ tpl/top-bottom_env.xsl

Comisión Económica para América Latina y el Caribe (2012b). Tercera Conferencia Regional Intergubernamental sobre Envejecimiento en América Latina y el Caribe. 
Recuperado de https://www.cepal.org/celade/noticias/paginas/2/46022/2012113-CRE.pdf

Comisión Económica para América Latina y el Caribe (2013). Conferencia regional intergubernamental sobre envejecimiento: hacia una estrategia regional de implementación para América Latina y el Caribe Plan de Acción Internacional de Madrid sobre el Envejecimiento. Recuperado de https://www.cepal.org/ celade/noticias/paginas/1/13611/FINAL-DSC-1-Espanol.pdf

Constitución Política de Colombia. Recuperado de http://www.corteconstitucional. gov.co/inicio/Constitucion\%2opolitica\%20de\%20Colombia\%20-\%202015.pdf

Dangond, C. (2015, octubre 17). La vejez es un naufragio. El Tiempo. Recuperado de http://www.eltiempo.com/archivo/documento/CMS-16406303

Declaración de Brasilia. Segunda Conferencia regional intergubernamental sobre envejecimiento en América Latina y el Caribe: hacia una sociedad para todas las edades y de protección social basada en derechos. Brasilia, 4 al 6 de diciembre de 2007. Recuperado de https://www.cepal.org/publicaciones/xml/o/3246o/LCG2359_e.pdf

Decreto 3771/2007, de 1 de octubre, por el cual se reglamenta la administración y el funcionamiento del Fondo de Solidaridad Pensional.

Decreto 3041/1966, 19 de diciembre, por el cual se aprueba el reglamento general del seguro social obligatorio de invalidez, vejez y muerte.

ElTiempo(2016, agosto7). El hogar es un gran epicentrodeviolencia. Recuperadodehttp:// www.eltiempo.com/justicia/cortes/violencia-en-el-hogares-de-colombia-31728

Huenchuan, S. (2013). Envejecimiento, solidaridad y protección social en América Latina y el Caribe. La hora de avanzar hacia la igualdad. Santiago de Chile: Cepal.

Informe medición de satisfacción de la ciudadanía Proyecto 742 “Atención Integral a personas mayores: disminuyendo la segregación y discriminación socioeconómica” Desarrollo de Capacidades y Potencialidades en Centros Día. Recuperado de http:// old.integracionsocial.gov.co/anexos/documentos/2015/encuestas/16122015_INFORME\%2OENCUENSTAS\%20CENTROS\%20DIA\%202015.pdf

Jaramillo, Á. M. y Forero, Á. L. (2015). De la política a la acción: estado y avances de la implementación de la política pública social para el envejecimiento y la vejez (PPSEV) en Bogotá. Papel Político, 2O(2), 295-322.

Jaramillo DeMendoza, A. M. (2017). Evolución de los arreglos residenciales en la vejez y sus determinantes: exploración basada en los censos colombianos, 1973 y 2005 (Tesis doctoral, Universidad Externado de Colombia, Bogotá, Colombia). 
Ley 90/1946, de 26 de diciembre, por la cual se establece el seguro social obligatorio y se crea el Instituto Colombiano de Seguros Sociales.

Ley 29/1975, de 25 de septiembre, por el cual se faculta al Gobierno Nacional para establecer la protección a la ancianidad y se crea el Fondo Nacional de la Ancianidad Desprotegida.

Ley 23/1981, de 18 de febrero, por la cual se dictan normas en materia de ética médica.

Ley 12/1987, de 27 de enero, por la cual se suprimen algunas barreras arquitectónicas y se dictan otras disposiciones.

Ley 105/1993, de 30 de diciembre, por la cual se dictan disposiciones básicas sobre el transporte, se redistribuyen competencias y recursos entre la nación y las entidades territoriales, se reglamenta la planeación en el sector transporte y se dictan otras disposiciones.

Ley 271/1996, de 7 de marzo, por la cual se establece el Día Nacional de las Personas de la Tercera Edad y del Pensionado.

Ley 294/1996, de 16 de julio, por la cual se desarrolla el artículo 42 de la Constitución Política y se dictan normas para prevenir, remediar y sancionar la violencia intrafamiliar.

Ley 361/1997, de 7 de febrero, por la cual se establecen mecanismos de integración social de las personas con limitación y se dictan otras disposiciones.

Ley 789/2002, de 27 de diciembre, por la cual se dictan normas para apoyar el empleo y ampliar la protección social y se modifican algunos artículos del Código Sustantivo de Trabajo.

Ley 882/2004, de 2 de junio, por medio de la cual se modifica el artículo 229 de la Ley 599 de 2000.

Ley 1091/2006, de 8 de septiembre, por medio de la cual se reconoce al colombiano y colombiana de oro.

Ley 1122/2007, de 9 de enero, por la cual se hacen algunas modificaciones en el Sistema General de Seguridad Social en Salud y se dictan otras disposiciones.

Ley $1171 / 2007$, de 7 de diciembre, por medio de la cual se establecen unos beneficios a las personas adultas mayores.

Ley 1251/2008, de 27 de noviembre, por la cual se dictan normas tendientes a procurar la protección, promoción y defensa de los derechos de los adultos mayores.

Ley 1257/2008, de 4 de diciembre, por la cual se dictan normas de sensibilización, prevención y sanción de formas de violencia y discriminación contra las mujeres, 
se reforman los códigos Penal, de Procedimiento Penal, la Ley 294 de 1996 y se dictan otras disposiciones.

Ley 1276/2009, de 5 de enero, a través de la cual se modifica la Ley 687 del 15 de agosto de 2001 y se establecen nuevos criterios de atención integral del adulto mayor en los Centros Vida.

Ley 1315/2009, de 13 de julio, por medio de la cual se establecen las condiciones mínimas que dignifiquen la estadía de los adultos mayores en los centros de protección, centros de día e instituciones de atención.

Ley 1438/2011, 19 de enero, por medio de la cual se reforma el Sistema General de Seguridad Social en Salud y se dictan otras disposiciones.

Ministerio de la Protección Social (2007-2019). Política Nacional de Envejecimiento y Vejez 2007-2019. Recuperado de https://www.minsalud.gov.co/Documentos\%20y\%2oPublicaciones/POL\%C3\%8DTICA\%2oNACIONAL\%2oDE\%20 ENVEJECIMIENTO\%20Y\%20VEJEZ.pdf

Ministerio de Salud y la Protección Social (2014-2024). Política Colombiana de Envejecimiento Humano y Vejez 2014-2024. Recuperado de https://www.minsalud. gov.co/sites/rid/Lists/BibliotecaDigital/RIDE/DE/PS/POCEHV-2014-2024.pdf

Ministerio de Salud y la Protección Social (s. f.). Metodología Integrada de Participación Social de y para Adultos Mayores (MIPSAM). Recuperado de https://www. minsalud.gov.co/proteccionsocial/promocion-social/Paginas/MetodologiaIntegrada-de-Participacion-Social-de-y-para-Adultos-Mayores\%E2\%80\%93MIPSAM-.aspx

Observatorio de Igualdad de Género de América Latina y el Caribe (s. f.). Indicadores destacados. Recuperado de https://oig.cepal.org/es

Organización de las Naciones Unidas (2002). Segunda Asamblea Mundial sobre el Envejecimiento (8-12 de abril 2002-Madrid, España). Recuperado de http:// www.un.org/es/events/pastevents/ageing_assembly2/

Organización de las Naciones Unidas (2002). Informe de la Segunda Asamblea Mundial sobre el Envejecimiento. Recuperado de http://www.monitoringris.org/ documents/norm_glob/mipaa_spanish.pdf

Organización de las Naciones Unidas (2003). Declaración Política y Plan de Acción Internacional de Madrid sobre el Envejecimiento. Nueva York: Organización de las Naciones Unidas. Recuperado de https://social.un.org/ageing-workinggroup/documents/mipaa-sp.pdf 
Organización de las Naciones Unidas (2011). Seguimiento de la Segunda Asamblea Mundial sobre el Envejecimiento: informe del Secretario General. Recuperado de http://www.un.org/es/comun/docs/?symbol=A/66/173

Organización de las Naciones Unidas (2015). Objetivos de Desarrollo Sostenible. Recuperado de http://www.un.org/sustainabledevelopment/es/mdgs/

World Values Survey (2012). Online data analysis. Recuperado de http://www.worldvaluessurvey.org/WVSOnline.jsp 


\section{Notas}

${ }^{1}$ Este artículo hace parte de la investigación de doctorado de la autora Evolución de las formas de organización residencial en la vejez: exploración basada en los censos colombianos 1973 y 2005. Las fuentes utilizadas en esta parte de la investigación son documentos institucionales y entrevistas a funcionarios e investigadores académicos. 2 Se realizaron once entrevistas a profesionales del nivel nacional, departamental, municipal y local. Para el caso de las entidades territoriales, no se recibió respuesta a la solicitud de estas. Las entrevistas hacen parte de dos investigaciones: De la política a la acción: estado y avances de la implementación de la política pública social para el envejecimiento y la vejez (PPSEV) en Bogotá y Envejecimiento demográfico, derechos humanos y protección social de la vejez: Colombia, 1951-2020, realizadas en el periodo de 2012 a 2014, en colaboración con el Instituto de Envejecimiento y Vejez de la Pontificia Universidad Javeriana. Los resultados de las investigaciones se encuentran disponibles en dicho instituto. El análisis que se hace de las entrevistas en este estudio no hace parte de los resultados de las investigaciones mencionadas, ni se ha publicado.

${ }^{3}$ Se realizaron cuatro entrevistas a expertos académicos que llevan más de diez años investigando sobre envejecimiento y vejez. Dos de ellas hacen parte de una serie de cuatro programas de radio que se hizo sobre las políticas públicas de envejecimiento y vejez en Colombia y Bogotá (programa Hologramas sociales, Javeriana Estéreo, 2012-2013).

${ }^{4}$ a) Salud y nutrición, b) protección de los consumidores ancianos, c) vivienda y medio ambiente, d) la familia, e) bienestar social, f) seguridad del ingreso y empleo y g) educación.

${ }^{5}$ Este principio se relaciona directamente con la familia: "10. Las personas de edad deberán poder disfrutar de los cuidados y la protección de la familia y la comunidad de conformidad con el sistema de valores culturales de cada sociedad" (p. 180).

${ }^{6}$ Compuesto por las cuestiones 1,4 y 8 .

${ }^{7}$ Cuestión 2.

${ }^{8}$ Cuestión 3 y 5 .

9 "Plan de Acción Internacional sobre Envejecimiento aprobado en Viena en 1982; los principios de las Naciones Unidas en favor de las Personas de Edad; Objetivos Globales sobre Envejecimiento para el año 2001 de la Asamblea General de Naciones Unidas aprobada en 1992 y el Comentario General N. ${ }^{\circ} 6$ adoptado por el Comité de Derechos Económicos, Sociales y Culturales en 1995" (Comisión Económica para América Latina y el Caribe [Cepal], 2002).

${ }^{10}$ General: Ley 1438/2011, 19 de enero; Ley 1315/2009, de 13 de julio; Ley 1251/2008, de 27 de noviembre; Ley 1257/2008, de 4 de diciembre; Ley 1122/2007, de 9 de enero; Ley 789/2002, de 27 de diciembre; y Ley 294/1996, de 16 de julio. Servicios de salud: Ley 361/1997, de 7 de febrero; Ley 105/1993, de 30 de diciembre; Ley 12/1987, de 27 de enero; Ley 1091/2006, de 8 de septiembre; Ley 882/2004, de 2 de junio; Ley 271/1996, de 7 de marzo. Salud mental: Ley 1438/2011, 19 de enero; Ley 1122/2007, de 9 de enero. Cuidadores: Ley 1251/2008, de 27 de noviembre. Consentimiento informado: Ley 23/1981, de 18 de febrero.

${ }^{11}$ En 2002, se establece el Sistema de Protección Social en Colombia por medio de la Ley 789/2002, de 27 de diciembre.

${ }^{12}$ Segundo borrador para consulta y consolidación final, enero de 2015.

${ }^{13}$ Se intentó contactar a los gestores territoriales de todos los departamentos del país, pero en la mayoría de los casos no se recibió respuesta y, con quienes se logró una comunicación, mencionaron que hasta ahora están validando la política y socializando el tema en sus territorios. Por el momento, gran parte de los territorios en el país cuentan solo con los Centros Día o Centros Vida (Ley 1276/2009, de 5 de enero), que se encuentran a cargo de las alcaldías y se financian con la estampilla, con los subsidios económicos de alimentación del Programa Juan Luis Londoño de la Cuesta y con el aporte en pensión de Colombia Mayor.

${ }^{14}$ Este es un desarrollo particular de la ciudad.

${ }^{15}$ La información detallada se encuentra en Jaramillo y Forero (2015).

${ }^{16}$ Colombia Mayor ofrece subsidios que van de COP 40000 a COP 75000 cada dos meses (Colombia Mayor Consorcio 2013). 